\title{
LAS INCERTIDUMBRES DEL CONSTITUCIONALISMO GLOBAL $^{1}$
}

\author{
STÉPHANE PINON \\ Profesor de Derecho Constitucional \\ Universidad de La Rochelle \\ Miembro del CERCOP de la Univ. de Montpellier
}

TRC, núm. 46, 2020, pp. 141-172

ISSN 1139-5583

\begin{abstract}
SUMARIO
I. La indeterminación doctrinal del concepto ante una realidad multiforme. II. El nacimiento de nuevas relaciones entre los poderes: la deriva hacía la oligarquía de los jueces. III. Una nueva combinación entre la depreciación del político y la centralidad del individuo. IV. El discurso de la convergencia de los derechos y el imperialismo cultural. V. Conclusión
\end{abstract}

El denominado «constitucionalismo global» puede concebirse de tres maneras.

En primer lugar, a través de un enfoque puramente descriptivo según el cual el concepto permite dibujar una nueva etapa en la historia del constitucionalismo. En sus orígenes el Derecho constitucional tenía como presupuesto ontológico al Estado, naciendo con el propósito de erigirse en frontera de la arbitrariedad real o imperial. Con posterioridad, el sufragio universal y los partidos políticos, tal y como los conocemos actualmente, trastornaron las concepciones tradicionales de la representación. Avanzando en el tiempo, tras la Segunda Guerra Mundial, la justicia constitucional y los derechos sociales pasan a constituirse en un nuevo elemento significativo del Derecho constitucional. Por su parte, en la actualidad nos encontramos ante una nueva etapa de su evolución: la de su instalación en un mundo globalizado,

1 Un primer acercamiento a esta temática lo desarrollamos en el trabajo «Les visages cachés du constitutionnalisme global», publicado en el libro colectivo coordinado por los profesores V. PEREIRA DA Silva, F. Balaguer Callejón (coords.), O constitucionaismo do séc. XXI na sua dimensão estadual, supranacional e global. Congresso em Honra de Peter Häberle, Lisboa, ICJP, 2015. 
caracterizado por los intercambios sin límites en todos los dominios, en los que las voluntades estatales entran en competencia con otros actores (las organizaciones internacionales, regionales, los mercados financieros, las Law Firms trans-nationales, las GAFAM, diferentes bancos autónomos...), perdiendo su papel protagonista en la determinación de las fuentes del derecho. En este mundo globalizado, las funciones esenciales del constitucionalismo - control de los poderes públicos y sobre todo protección de las libertades fundamentales - solo se realizan imperfectamente a nivel estatal, de modo que se precisa la intervención de instituciones supra o para-estatales. Se observa claramente un fenómeno tangible de «desestatización».

Se puede también, por otro lado, enfocar el «constitucionalismo global» desde un punto de vista mucho más estratégico o prescriptivo. No basta con dar cuenta de las metamorfosis de la realidad, sino que es preciso incorporarlas en una visión ideológica preestablecida. Al usar el vocabulario del Derecho constitucional (una asignatura que, como apuntó Häberle, ganó definitivamente sus títulos de nobleza con la «victoria mundial» de la justicia constitucional ${ }^{2}$ ), los partidarios del constitucionalismo global intentarían sublimar la realidad ${ }^{3}$ : creando la ilusión de la legitimidad de la gobernanza mundial, superando la ausencia de legitimidad «formal» de las instituciones internacionales, buscando modificar el contenido de la normas al nivel supranacional y la manera de aplicarlas (a través del principio de proporcionalidad por ejemplo). Al fin y al cabo, este abuso de lenguaje escondería un proyecto imperialista de los constitucionalistas. Estaríamos en plena competencia académica. Anne Peters lo dice sin rodeos: «El constitucionalismo global es una agenda política y académica que identifica y defiende la aplicación de los principios constitucionalistas en la esfera jurídica internacional para mejorar la efectividad y la justicia del orden jurídico internacional» ${ }^{4}$. Pero un concepto - constitucionalismo- que quiere abarcar todo es un concepto que no dice nada.

El «constitucionalismo global» también puede entenderse de manera utópica (o fantaseada). Es un proyecto por el futuro a la manera del libro de Kant, Hacia la paz perpetua (1795). Así, autores como Jürgen Habermas5, Daniele

2 P. Häberle, L'Etat constitutionnel, Presses Universitaires d'Aix-Marseille, Economica, coll. Droit public positif, 2004, p. 140. Véase también, D. VALADES (Dir.), Conversaciones académicas con Peter Häberle, México, UNAM, 2006, p. 2.

3 Cabe citar a quienes ven la Carta de las Naciones Unidas como una verdadera Constitución (B. FAssBENDER, TH. Franck), como el índice de una constitucionalización del orden jurídico mundial (A. Peters) o como la manifestación del desarollo de una Constitución mundial «material» (E. DE WET, CH. TomUsСНАт). Con enfoques epistemológicos diferentes, podemos citar la obra del sociólogo G.r TeubNER sobre el «constitucionalismo societal» (Constitutional fragments: Societal constitutionalism and globalization. Oxford, Oxford University Press, 2012).

4 A. Peters, «Los méritos del constitucionalismo global», Revista Derecho del Estado, n. ${ }^{\circ}$ 40, 2018, p. 4. También J. Klabbers, A. Peters, G. Ulfstein, The Constitutionalization of International Law, Oxford University Press, Oxford, 2009.

5 Por ejemplo, J. Habermas, «The Constitutionalization of International Law and the Legitimation Problems of a Constitution for World Society», Constellations, vol. 15, 2008, p. 449 o del mismo autor, The Postnational Constellation. Political Essays, Cambridge, MIT Press, 2001. 
Archibugi ${ }^{6}$ o Luigi Ferrajoli ${ }^{7}$ sueñan con lograr — cada uno a su manera- una «democracia cosmopolita» con una participación de todos los ciudadanos de todos los pueblos, facilitado por la presencia de un «espacio público global»y aun de un Parlamento mundial. No habría en suma nada más que esperar del único orden constitucional estatal, ni en materia de protección de los individuos ni en materia de paz entre los pueblos; en cambio habría todo un tesoro esperando tras el advenimiento de un constitucionalismo globalizado, reflejo de un mundo sin fronteras, liberado de la plena soberanía de los Estados. Estos discursos se acercan de un llamamiento en favor de un giro hacia el global (a «cosmopolitan turn»). Un conjunto de «quimeras académicas» podría insinuar la crítica.

Pero el «constitucionalismo global» no es sólo un paradigma académico, sino que representa un desafío por el futuro del propio Derecho constitucional. Ante las nuevas amenazas por los derechos humanos (la protección de la vida privada en la sociedad digital, la protección de la salud en el mundo de la liberalización salvaje del comercio, el aplastamiento de los derechos sociales por los mercados financieros...), ante la multiplicación de lugares transnacionales muy poderosos de decisiones (la soberanía numérica, las agencias de calificación, las Bancas internacionales, los grupos industriales que abusan de los recursos naturales como el gigante Odebrecht...), el Derecho constitucional pierde en buena medida el contacto con sus misiones tradicionales. En presencia de tales realidades debe transformarse, debe salir de la esfera estatal si quiere sobrevivir con utilidad. Muchos poderes (sobre todo económicos) se desgajan de las fronteras nacionales; a nuestro juicio, hace falta que el constitucionalismo los siga ${ }^{8}$.

\section{LA INDETERMINACIÓN DOCTRINAL DEL CONCEPTO ANTE UNA REALIDAD MULTIFORME}

El constitucionalismo global en la doctrina. No se trata de un concepto presente en el lenguaje del derecho positivo (empleado en los tratados internacionales, por

6 D. Archibugi, D. Held (eds.), Cosmopolitan Democracy: An Agenda for a New World Order, Cambridge: Polity Press, 1995; D. ArChibugi, The Global Commonwealth of Citizens ; Towards Cosmopolitan Democracy, Princeton University Press, 2008 ; D. ArChibugI, «Cosmopolitan Democracy : A Restatement», Working Paper, 2011, accesible sobre SSRN, 15 p.

7 El filósofo del derecho italiano participó, por ejemplo, en el gran Congreso que tuvo lugar en Roma, en febrero de 2020, para reflexionar sobre la idea de una Constitución de la Tierra como herramienta de gobernanza global. En su opinión, una Constitución mundial obligaría a proteger la igualdad, el derecho a la no discriminación o la salud. Derechos que pertenecen a «la esfera de lo no decidible» y que no pueden quedar a merced de las mayorías (cit. en El Pais, de 5 de abril de 2020).

8 En esta misma revista puedes verse, bien desde una perspectiva global bien más acotados al Derecho constitucional español, los trabajos de los profs. G. DE VERGOTTINI, «Garantía de la identidad de los ordenamientos estatales y límites de la globalización», Teoría y Realidad Constitucional, n. ${ }^{\circ}$ 18, 2006, G. MAESTRO Buelga, Teoría y Realidad Constitucional, n. ${ }^{\circ}$ 7, 2001 y Aláez Corral, B., «Globalización jurídica desde la perspectiva del Derecho constitucional español», Teoría y Realidad Constitucional, n. ${ }^{\circ}$ 40, 2017. 
los constituyentes o por el legislador ordinario), sino de un concepto construido por la doctrina —especialmente la anglosajona' ${ }^{9}$ - para hablar del derecho; se asemeja a una especie de «metalenguaje». El concepto de «Constitucionalismo global» es reciente, aún muy discutido, podríamos decir que en gestación, de modo que el empleo de estas dos palabras no concita adhesión común sobre sus características propias. No hay una definición comúnmente admitida, ni siquiera un ámbito común de investigación. Pertenecen los conflictos de frontera con el Derecho internacional, aun con las diferentes variantes del «constitucionalismo multinivel». El constitucionalismo global de Thomas Kleinlein, de Anne Peters o de Bardo Fassbender no es el de Jürgen Habermas o de Gunther Teubner. En el diario de Oxford (International Journal of Constitutional Law), Christine Schwöbel-Patel habla por ejemplo de los cuatro dimensiones de este tipo de constitucionalismo en la doctrina (social, institucional, normativa y analogica ${ }^{10}$ ), y prefiere sostener la tesis de un organic global constitutionalism ${ }^{11}$. Así, no es sorprendente que la frontera entre el global constitutionalism, el multilevel Constitutionalism (la traducción de la noción de Verfassungsverbund elaborada por Ingolf Pernice y su escuela alemana), la cosmopolitan Constitution ${ }^{12}$, el transconstitutionalism ${ }^{13}$ o el pluralismo del constitucionalismo internacional ${ }^{14}$ no sea fácil de trazar en el lenguaje científico.

Se trata, pues, de un concepto muy maleable, con un alcance científico incierto, incapaz de lograr una unidad descriptiva en esta etapa de su evolución. ¿Cómo podría hacerlo ante realidades a describir tan fragmentadas y heterogéneas (derecho humanitario, universalización de los derechos fundamentales, diálogo de los jueces, constitucionalización de la ONU, de la OMC, de los actores internacionales privados etc.)? El cambio de escala acarrea un cambio del objeto de estudio.

A pesar de todo, este discurso está arraigando cada vez más en la doctrina lo que lleva a la necesidad de tomarlo en serio. De efecto, los autores que se refieren directamente o no a la llegada del «constitucionalismo global» son numerosos:

9 ¿Cómo explicarlo? Podemos avanzar dos razones. Porque, antes que los «constitucionalistas», fueron los «internacionalistas» los que comprobaron primero una evolución del derecho internacional cada vez más invadido por los derechos individuales (así como la presencia de cláusulas internacionales en las constituciones nacionales). Además, el concepto de «Estado» es menos presente en la doctrina constitucional anglosajona, lo que permite enfocar el constitucionalismo supra o infra estatal con más facilidades.

10 Cfr. «Situation the Debate on Global Constitutionalism», International Journal of Constitutional Law, Vol. 8, Issue 3, July 2010, p. 611 (https://academic.oup.com/icon/article/8/3/611/623473).

11 Cfr. «Organic Global Constitutionalism», Leiden Journal of International Law, Vol. 23(3), 2010, p. 529. Del mismo autor : Global Constitutionalism in International Legal Perspective, Martinus Nijhoff Publishers, 2011.

12 A. Somek, The Cosmopolitan Constitution, Oxford, Oxford University Press, 2014. Véase también A De Julios-Campuzano, El horizonte constitutional. Ciencia jurídica, Derechos humanos y constitucionalismo cosmopolita, Madrid, Dykinson, 2014.

13 M. Neves, Transconstitucionalismo, São Paulo, 2009 (trad. inglés, ed. Hart Publishing, 2013).

14 Véase el profundo estudio de A. J. RoDrigo «El pluralismo del constitucionalismo internacional», Anuario español de derecho internacional, vol. 29, 2013, p. 61. 
desde Bruce Ackerman, Thomas M. Franck, Mireille Delmas-Marty, hasta los trabajos más recientes de Mattias Kumm, Rafael Domingo, Gabor Halmai o Aydin Atilgan ${ }^{15} \ldots$ Cabe destacar, por ejemplo, el nacimiento de una revista en Cambridge, hace casi una década, titulada: Global Constitutionalism. Human Rights, Democraty, Rule of Law ${ }^{16}$. O la iniciativa del Instituto Max Planck de Berlín que sostiene un proyecto de investigación liderado por Anne Peters ( Global constitutionalism and Global Governance» ${ }^{17}$ ); incluso el congreso organizado sobre el tema por el centro Michel Villey de Paris II a pesar de su habitual repliegue sobre la historia constitucional y la grandeza del Estado ${ }^{18}$ o la reciente traducción en castellano del libro de Luigi Ferrajoli Constitucionalismo más allá del Estado ${ }^{19}$.

El constitucionalismo global en los hechos. Si se respetan unas premisas metodológicas, se puede admitir que más allá de los discursos el constitucionalismo global se pone de manifiesto en su vertiente fáctica. Diversos fenómenos lo prueban. Por ejemplo, tenemos la apertura de las constituciones estatales a las normas internacionales, lo que Peter Häberle califica de «Estado constitucional cooperativo» ${ }^{20}$, lo que, por su lado, Boris Mirkine-Guetzévitch había calificado al inicio de los años treinta del pasado siglo de «Derecho constitucional internacional $»^{21}$. Resulta una inevitable erosión de la soberanía de los Estados. El principio de proporcionalidad pasa de la esfera del contencioso constitucional hasta su implantación en la práctica

15 B. Ackerman, «The Rise of World Constitutionalism», Occasional Papers, 1996 (https://digitalcommons.law.yale.edu/ylsop_papers/).; T. M. FrANCK, «Is the UN Charter a Constitution?», J. A. FroweIN/ K. Scharioth/ I. WinkelmanN / R. Wolfrum (coord.), Verhandeln für den Frieden Negotiationg for Peace, Liber Amirocum Tono Eitel, Berlin, Springer, 2003 ; M. Delmas-Marty, Les forces imaginantes du droit, Seuil en cuatros volúmenes : Le relatif et l'universel, 2004, Le Pluralisme ordonné, 2006, La refondation des pouvoirs (2007); Vers une communauté de valeurs, 2011; M. Kumm, «The Cosmopolitan Turn in Constitutionalism: An Integrated Conception of Public Law», Indiana Journal of Global Legal Studies, 623, 2013; "The legitimacy of International Law: A Constitutionalist Framework of Analysis», European Journal of International Law, vol. 15, 2004 (cabe mencionar también que M. KUMm dirige desde 2012 el «Centro de constitucionalismo Global» de la Berlin Social Science Center); R. Domingo, The New Global Law, Cambridge University Press, 2011; G. Halmai, Perspectives on Global Constitutionalism: The Use of Foreign and International Law, Eleven International Publishing, 2014.; A. Atilgan, Global constitutionalism. Socio-legal Perspective, Berlin, ed. Springer, 2017.

16 http://journals.cambridge.org/action/displayJournal?jid=GCN.

17 Pueden verse sus últimas publicaciones: T. Suami/ M. Kumm/ A. Peters/ D. Vanoverbeke (coord), Global Constitutionalism from European and East Asian Perspectives, Cambridge University Press, Cambridge, 2018 ; o A. Peters, E. Lagrange, S. Oeter, CH. Tomuschat (coord.), Immunities in the Age of Global Constitutionalism, Brill Nijhoff, Leiden, 2015.

18 Publicado en la revista Jus Politicum (n. ${ }^{\circ}$ 19, 2018, «Constitutionalisme global», http://juspoliticum.com.).

19 Edición Trotta, Madrid, 2018 (trad. A. IBAÑEz).

20 Se encuentra este concepto («Der kooperative Verfassungsstaat») de P. HÄBERLE en una compilación de escritos titulada Die Verfassung los Pluralismus, Athenäum, Königstein/Ts., 1980, p. 306. Del mismo autor, véase también L'Etat constitutionnel, Economica, coll. Droit public positif, 2004, p. 61.

21 Es el título de una famosa obra publicada en 1933 (ed. Sirey). Mirkine estaba convencido de que la constitucionalización de la fuerza obligatoria del derecho internacional (que figura en su época en numerosas constituciones de Europa central) conduciría al mantenimiento de la paz entre los pueblos. Para más detalles sobre este autor, véase S. PINON, «Boris Mirkine-Guetzévitch et la diffusion du droit constitutionnel», Droits. Revue française de théorie, de philosophie et de culture juridiques, n. ${ }^{\circ}$ 46-2007, p. 183. 
de las jurisdicciones transnacionales, transformándose en una foundational tenet of global constitutionalism ${ }^{22}$. Observamos un advenimiento del individuo y de sus derechos al nivel internacional, casi un proceso continuo de «humanizar la soberanía» (la Declaración universal de los derechos humanos, la Convención interamericana de derechos humanos, los «estándares constitucionales» defendidos por la Comisión europea para la democracia y por el derecho ${ }^{23} \ldots$... La internacionalización del «diálogo de los jueces» se desarrolla también; un dialogo multinivel entre tribunales nacionales e internacionales o supranacionales, como es el caso entre jueces y tribunales nacionales ordinarios o constitucionales con el Tribunal Europeo de Derechos Humanos (TEDH) o en América con la Corte Interamericana de Derechos Humanos (CIDH); como asimismo, puede darse como un diálogo entre tribunales internacionales o supranacionales, por ejemplo entre cortes regionales de derechos humanos ${ }^{24}$. Incluso la Banca Mundial exige la protección de los derechos humanos y de la democracia pluralista cuando otorga ayudas ${ }^{25}$. Diferentes autores observan la presencia de estándares del constitucionalismo global que influyen en la redacción de nuevas constituciones nacionales, que resultan útiles tanto para favorecer la integración exterior del país (compartiendo los mismos principios con la comunidad internacional) como para apoyar su legitimidad interior. Tipos de «micro constitucionalización» se forman fuera de los Estados, al menos sobre el plano material. Las mutaciones se amplían rápidamente en la esfera estatal (que pierde o transfiera muchas de sus competencias tradicionales) y en la esfera de los órganos internacionales, lo que implica mutaciones en las asignaturas correspondientes (el Derecho constitucional y el Derecho internacional).

Además, existe la tentación de constitucionalizar la actividad de nuevos actores internacionales, el nuevo «constitucionalismo social global» (societal constitutionalism global) en palabras de Gunther Teubner. El autor funda sus observaciones sobre la articulación de un proceso de «auto-constitucionalización» de sectores autónomos de la sociedad mundial. Así, considera que numerosos actores privados se sometan - a través de unas clases de «constituciones "civiles"»— al respeto de los derechos humanos, de la misma manera que los poderes públicos tradicionales. Un pluralismo constitucional mundial tomaría forma, de manera fragmentada, y estaría integrado simultáneamente por constituciones «políticas» y constituciones «civiles» ${ }^{26}$. Según el autor, este fenómeno de auto-constitucionalización se pone

22 A. S. Sweet y J. Mathews, «Proportionality Balancing and Global Constitutionalism», Columbia Journal of Transnational Law, n. ${ }^{\circ}$ 47, 2008, p. 73. También A. BARAK, Proportionality: Constitutional Rights and their Limitations, Cambridge, Cambridge University Press, 2012.

23 La conocida «Comisión de Venecia» que ejerce su influencia de manera global con sus sesenta y dos miembros a día de hoy.

24 J. García Roca, P. A. Fernández Sánchez, P. Santoyala Machetti y R. Canosa Usera (coord.), El Diálogo entre los Sistemas Europeo y Americano de Derechos Humanos, Pampelune, Civitas, 2012.

25 Aunque lo cierto es que lo hace todavía de manera insuficiente según denuncia Human Rights Watch.

26 G. Teubner, Constitutional fragments: Societal Constitutionalism and Globalization, op. cit. Para una puesta en perspectiva de sus trabajos en la constelación de las nuevas variantes del constitucionalismo (el «neo», el 
de manifiesto, por ejemplo, en la lex mercatoria para las empresas, en la regulación de Internet o en la lex sportiva con el todopoderoso Tribunal Arbitral del Deporte. El caso Abdullab Kadi $i^{27}$ o el caso Achema $B V^{28}$ suponen otros ejemplos de un contencioso típicamente constitucional que excede del ámbito estatal para alcanzar la actividad de las organizaciones internacionales.

Pero, admitir que todos estos nuevos fenómenos jurídicos pertenecen a la clase del «constitucionalismo» supone abandonar al menos cuatro pilares teóricos de la disciplina. El primero es la interdependencia «genética» entre Estado y constitución. El segundo es el vínculo entre el poder político y la constitución que sugiere abandonar además el vínculo entre poder constituyente popular y constitucionalismo. El tercer pilar impugnado se sitúa en la depreciación del criterio formal en la definición del Derecho constitucional. El cuarto consiste en borrar el concepto de «soberanía» de la gramática del constitucionalismo. No hay una prohibición conceptual que lo imposibilite.

Si se admite esta revolución teórica y epistemológica — lo que no me parece fácil- se puede afirmar que el derecho constitucional se desarrolla ahora en dos direcciones. Sigue, por una parte, de manera clásica pero cada vez más intensa, regulando la vida política de los Estados. El papel central que ocupa hoy día la justicia constitucional en las sociedades democráticas lo ilustra perfectamente. Se podría también citar la resurgencia del tema de las «identidades constitucionales», así como el brusco despertar de la unilateralidad estatal cuando surge la necesidad de luchar contra el terrorismo o contra una pandemia... Por otra parte, el Derecho constitucional intenta imponer — en una evolución mucho más reciente - la salvaguardia de derechos humanos a los poderes transnacionales, cada vez más numerosos en esta globalización policéntrica ${ }^{29}$. En esta perspectiva, los nuevos centros de decisiones liberados de las fronteras estatales, incluyendo tanto a las empresas multinacionales, los mercados financieros, las organizaciones internacionales, como a las redes de expertos intervinientes, se verían sujetos por el respeto al concepto de dignidad humana.

Sin embargo, el constitucionalismo, en su vertiente «global» sigue siendo embrionario, incompleto, reducido en varios de sus aspectos definitorios. De facto, debe ante todo analizarse como un constitucionalismo de protección de los

«nuevo», el «trans», el «multilevel» etc.), véase J.J. Gomes CANOTILHo, «Principios y «nuevos constitucionalismos». El problema de los nuevos principios», Revista de Derecho Constitucional Europeo, n. ${ }^{\circ}$ 14, 2010, pp. 321-364.

27 TJUE, 3 de septiembre de 2008, Yassin Abdullab Kadi et Al Barakaat International Foundation c.l Consejo y Comisión (C-402/05 P et C-415/05 P).

28 TJUE, 6 de marzo de 2018, Slovak Republic v. Achmea BV (C-284/16, ECLI:EU:C:2018:158).

29 Obviamente, este enfoque renovado del constitucionalismo supone devolver a la sociología un papel importante. Lo que permite así comprobar la actualidad de los escritos de G. SCELLE («Le droit constitutionnel international», en M. Carré De Malberg, Sirey, 1933, p. 503), muy cercanos en cierto modo a los de G. Teubner. El constitucionalismo así concebido tendría según sus defensores el potencial para contrarrestar las tendencias expansionistas de los sistemas sociales fuera del ámbito estatal, en materia económica, tecnológica o los medios de comunicación, especialmente cuando estos sistemas ponen en peligro la autonomía individual. 
derechos humanos sin garantías institucionales suficientes todavía ${ }^{30}$. Al fin y al cabo, solo el sistema del Convenio europeo de los derechos humanos parece ofrecer un modelo logrado. Pero más grave que un simple problema de crecimiento, son las dificultades de fondo, que amenazan la esencia del constitucionalismo global. Dicho de otra manera, ¿cuáles son los rostros ocultos del constitucionalismo global? Procede destacar tres. En primer lugar, este desarrollo de la globalización jurídica favorece una nueva relación entre los poderes, relación dominada por la oligarquía de los jueces. En segundo lugar, el fenómeno fomenta una nueva visión de la sociedad, que combina la depreciación del «político» y la centralidad del individuo. En tercer lugar, hay que desconfiarse de una tendencia muy arraigada en Occidente, la que consiste en generalizar una «filosofía doméstica», fomentando así el triunfo de un cierto colonialismo cultural de los derechos humanos.

\section{EL NACIMIENTO DE NUEVAS RELACIONES ENTRE LOS PODERES: LA DERIVA HACÍA LA OLIGARQUÍA DE LOS JUECES}

En la actualidad, no es posible evocar el constitucionalismo global sin hablar de activismo jurídico, de Judicial Globalization (según las palabras de Anne-Marie Slaughter ${ }^{31}$ ), o de «cosmopolitismo jurídico» ${ }^{32}$, lo que acredita la idea de una verdadera comunidad global de los tribunales. Fue ese el objetivo de Norman Dorsen y Michel Rosenfeld creando la revista International Journal of Constitutional Law hace casi una década: entender mejor el uso creciente de los análisis comparados en las decisiones de las Cortes constitucionales ${ }^{33}$. Adoptando una postura menos optimista, también parece difícil hablar de constitucionalismo global de los derechos sin pensar en la fórmula de Robert Michels: una especie de «Ley de hierro de la oligarquía» de los jueces. ¿Por qué esta forma oligarquica de gobierno puede ser inevitable? Debido a tres elementos: la importancia del papel de los jueces en la globalización, la naturaleza de su función y la manera en que la ejercen.

\section{La importancia del papel del juez}

La globalización supone la apertura de los ordenamientos jurídicos. Pero quienes se sitúan en primera línea para poner en práctica esta nueva articulación

30 S. Hennette-Vauchez y J.M. Sorel (coord.), Les droits de l'bomme ont-ils constitutionnalisé le monde?, Bruxelles, Bruylant, 2011.

31 Cfr. "Judicial Globalization», Virginia Journal of International Law, vol. 40, 2000, p. 1103. También cabe consultar su libro: A New World Order, Princeton University Press, 2004. En la misma linea véase: J. Allard y A. GARAPON (coord.), Les juges dans la mondialisation. La nouvelle révolution du droit, Paris, Seuil, 2005.

32 G. Pisarello Prados, «Globalizacion, constitucionalismo y derechos: las vías del cosmopolitismo jurídico», en A. De Cabo De la Vega, G. Pisarello (coord.), Constitucionalismo, mundializacíon y crisis del concepto de soberanía. Algunos efectos en América latina y en Europa, Universidad de Alicante, 2000, p. 23.

33 Cfr. «Note to Readers», vol. 1, 2003, p. 1 (https://academic.oup.com/icon/issue/1/1). 
son los jueces. A través de los procesos concretos son ellos los que desempeñan un papel clave de conexión en la globalización, entre los ordenamientos jurídicos estatales y el nuevo derecho global. En este sentido, la Unión Europea puede aparecer como un verdadero laboratorio. «Escondido en el país de hadas del Gran Ducado de Luxemburgo y bendecido con benigno descuido por los poderes que son y los medios de comunicación, el Tribunal de Justicia creó un nuevo ordenamiento jurídico de arquitectura federal...» ${ }^{34}$.

La integración nunca habría sido posible sin la jurisprudencia del Tribunal de Justicia —imponiendo los principios de «aplicabilidad inmediata» y de «primacía» del derecho comunitario desde el comienzo de los años sesenta-, sin la práctica de la cuestión prejudicial por los jueces nacionales, sin los golpes de audacia del Tribunal Constitucional alemán (las sentencias Solange I de 1974 o Maastricht de 1993 que le permite rebelarse contra los ultra vires de los jueces de Luxemburgo), sin las jurisprudencias Nicolo o Perreux en Francia, etc. El antiguo juez Robert Lecourt tenía razón al titular su libro L'Europe des juges (1976) ${ }^{35}$. La historia es bien conocida. Debido a la ausencia de catálogo genérico de derechos fundamentales, fue el Tribunal de Justicia el que inauguró el concepto de «tradiciones constitucionales comunes» (decisión Stauder del 12 de noviembre de 1969). El año siguiente, en la famosa sentencia Internationale Handelsgesellschaft afirmó que «la salvaguardia de dichos derechos, aunque se inspire en las tradiciones constitucionales comunes a los Estados miembros, debe ser garantizada en el marco de la estructura y de los objetivos de la Comunidad». Así nació la jurisprudencia muy constructiva alrededor de los «principios generales del Derecho comunitario» (sentencias Nold, Hauer, Nacional Panasonic etc.)

El instrumento comparativo aparece a la vez como una técnica de cooperación con los jueces nacionales y como una técnica de legitimación del nuevo orden jurídico creado. Interpretando las disposiciones demasiado generales de los tratados $^{36}$ y de las constituciones respeto a las relaciones entre los ordenamientos jurídicos, son forzosamente los jueces los que garantizan la conexión entre el espacio estatal y el espacio europeo o global. En el espacio supranacional, europeo o global, aparecen entonces como los actores principales de un constitucionalismo que se desgaja del territorio estatal. En cierto modo, parecen ocupar el vacío dejado por un imposible poder constituyente transnacional. Ran Hirschl habla por su lado de una tendencia mundial a la «Juristocracy» ${ }^{37}$. Estos análisis, basadas en un trabajo comparado entre Canadá, Nueva Zelanda,

34 E. STEIN, «Lawyers, Judges and the Making of a Transnational Constitution», American Journal of International Law, 1981, p. 1.

35 Bruxelles, Bruylant, 1976. Reedición en 2008 (coll. Droit de l’Union européenne).

36 Véase por ejemplo el conocido art. 4.2 TUE : «La Unión respetará la igualdad de los Estados miembros ante los Tratados, así como su identidad nacional, inherente a las estructuras fundamentales políticas y constitucionales de éstos, también en lo referente a la autonomía local y regional...».

37 R. Hirschel, Towards Juristocracy. The Origins and consequences of the New Constitutionalism, Cambridge, Harvard University Press, 2007. 
Israel, Sudáfrica merecen sin duda ser leídos. Si no compartimos la idea de una connivencia entre los intereses particulares de una pequeña elite y el auge de las Cortes $^{38}$, se pone de manifiesto que las sentencias de los actores jurídicos al nivel supranacional favorece el alejamiento de las decisiones políticas mayoritarias (a través de los parlamentos o de los referendos). Dicho de otro modo, detrás del entusiasmo que genera el «judicial review» se esconde un miedo de la decisión popular, una especie de desconfianza en la democracia electoral ${ }^{39}$. Es el encubrimiento de la dimensión «política» de las constituciones el que prevalece.

Y como resulta imposible denunciar una cuadrícula jurisprudencial establecida en torno a la universalización de los derechos humanos, resulta difícil criticar el papel de los jueces. En suma, ellos encarnan la cara positiva, la cara noble de la globalización. ¿Tienen la legitimidad suficiente para esa misión? La cuestión debe plantearse.

\section{La naturaleza de su misión}

La omnipotencia de los jueces en este derecho globalizado se basa en la interpretación de los grandes principios: el derecho a la vida, la dignidad de la persona, la no discriminación, la libertad de prensa, la igualdad de género, etc. Pero el principio no es la regla ${ }^{40}$. A la indeterminación de las fuentes del principio se añade una escala de valores que depende más de la moral, de la cultura propia de los miembros de las jurisdicciones, que de la jerarquía formal de las normas. La indeterminación de estas fuentes es tal que el uso de los principios supone siempre una ponderación, un control de proporcionalidad. Sin embargo, encontrándonos en la edad del balancing, el razonamiento jurídico da un papel cada vez más claro al poder discrecional de los jueces.

Como lo señala Guillaume Tusseau «Una jurisprudencia de principios puede y debe reelaborarse siempre. Como mandato de optimización, los principios siempre se pueden promover y respetar más. La perfección sigue siendo difícil de alcanzar, por lo que siempre parece apropiado emprender nuevas acciones legales. A diferencia de las reglas en conflicto, donde una de ellas debe necesariamente ser

38 «I would therefore suggest that the current global trend toward judicial empowerment through constitutionalization is part of a broader process, whereby self-interested political and economic elites, while they profess support for democracy and sustained development, attempt to insulate policy making from the vagaries of democratic politics» (R. HIRSCHL, «The Political Origins of the New Constitutionalism», Indiana Journal of Global Legal Studies, vol. 11, 2004, p. 107).

39 Me refiero aquí a un libro clásico y fundamental en los Estados Unidos: J.H. Ely, Democracy and Distrust. A Theory of Judicial Review, Harvard University Press, Cambridge, 1980.

40 Sobre la especificidad de los "principios», véase R. Dworkin, Prendre les droits au sérieux, PUF, 1995, p. 73. También G. Zagrebelsky, Il Diritto Mite, Turin, Einaudi, 1993, pp. 148 ss. 
declarada inválida, en su totalidad o en parte, los principios nunca son «perdedores» de manera definitiva» ${ }^{41}$.

La seguridad jurídica y la previsibilidad del derecho se encuentran amenazadas. ¿Tienen los jueces competencia suficiente para entrar en esta lógica de «better regulation»? Se desarrolla toda una doctrina que pone de relieve las limitaciones del trabajo de los jueces en términos de formación y documentación, esto es, capacidad para enfocar el alcance moral, social o psicológico de los arbitrajes ${ }^{42}$. Además, nadie puede asegurar que la pluralidad de la sociedad —a fortiori en el espacio internacional - se refleje mejor en los tribunales; que la edad media de los jueces, la naturaleza de sus formaciones o su extracción sociológica permitan sentir mejor las necesidades de la pluralidad social y cultural. Y no hablamos del clientelismo o de las estrategias políticas de los jueces mismos o de quien los promueven o nombran. El constitucionalismo global de derechos humanos revela con fuerza el mito de una lógica pura y mecánica en el proceso judicial, que convierte en ilusión la idea de una neutralidad normativa del juez, la idea de que pueda declarar el derecho sin hacer obra de creación. Los partidarios de la teoría realista de la interpretación lo demuestran: el trabajo de interpretación de los textos - respecto sobre todo a las normas ambiguas, redactadas en términos imprecisos o bajo la forma de principios, numerosos en las normas constitucionales- no es una operación de conocimiento, es sobre todo una operación de voluntad; una voluntad que integra argumentos jurídicos, pero también argumentos personales y de manera inevitable, argumentos políticos. Desde luego, ¿quién puede asegurar que, en un espacio global, sin real control de la prensa o de la opinión, los jueces darán siempre la prioridad a los derechos sociales o a las poblaciones oprimidas? ¿Qué tipo de responsabilidad organizar por ellos al nivel supranacional?

\section{La manera de ejercer su misión}

La oligarquía se alimenta del famoso «diálogo de los jueces». Los actores constitucionales parecen convivir e interactuar pacíficamente. Stephen Breyer habla de «diplomacia judicial» para referirse a la circulación de los estándares de razonamiento jurídico y a la universalización de los derechos fundamentales ${ }^{43}$.

41 G. Tusseau, «Un Chaos conceptuel qui fait sens : la rhétorique du constitutionnalisme global», J.-Y. Cherot y B. Frydman, La science du droit dans la globalisation, Bruxelles, Bruylant, coll. Penser le droit, 2012, p. 207.

42 P. Yowell, Constitutional Rights and Constitutional Design: Moral and Empirical Reasoning in Judicial Review, Hart Publishing, 2018. Para otro tipo de rehabilitación del trabajo en las asambleas: G. TUSSEAU, «Parlement et droit fondamentaux», O. Rozenberg, E. Thiers (dir.), Traité d'études parlementaires, Bruxelles, Bruylant, 2018, p. 194.

43 S. Breyer, The Court ans the world: American Law and the New Global Realities, New York, Alfred A. Knopf, 2015, p. 382. 
Joseph Weiler incluso habla del principio de «tolerancia constitucional» ${ }^{44}$, mientras que Marcelo Neves evoca el abandono de todo «narcisismo» de las esferas constitucionales ${ }^{45}$. Las citas cruzadas entre las jurisdicciones constitucionales se desarrollan, formando al tiempo una especie de «racionalidad parcialmente común y transversal» ${ }^{46}$ que tomaría consistencia. Mientras que los razonamientos jurídicos se fortalecen, crecen nuevos métodos comunes de interpretaciones. ¡Pero el cuadro es demasiado atractivo para poder contener toda la verdad! Si bien el diálogo de los jueces fue fuente de progreso en el fortalecimiento de la protección de los derechos, especialmente en el espacio europeo ${ }^{47}$, la retórica del «diálogo» no es una fórmula neutra; antes bien está inevitablemente al servicio de sus protagonistas. Por ejemplo, recurrir al argumento de derecho comparado para los jóvenes tribunales constitucionales (este fue el caso en Sudáfrica o en Hungría durante la década 90) es una forma de afianzar la legitimidad de las soluciones jurisprudenciales seleccionadas. Así los jueces pueden protegerse de la acusación según la cual la resolución de conflictos entre diferentes normas depende de un puro acto de voluntad. En Europa, emplear el término «diálogo» ofrece a los jueces nacionales — con más frecuencia a la doctrina— la ilusión de una independencia preservada ${ }^{48}$. Se oculta de esta manera una realidad que a menudo se parece a una red vertical partiendo de la CEDH, a un diálogo de sordos o a un «monólogo»... Por último, la retórica del «diálogo» sirve para valorar el estatuto propio de los jueces, para poner de relieve sus pretendidas virtudes, incluso para justificar su omnipotencia. La globalización en lo que a los jueces se refiere no es la competencia ni siquiera la guerra, es el diálogo, el reinado de las relaciones

44 Véase, por ejemplo, J.H.H. WeILER, «Federalism Without Constitutionalism: Europe's Sonderweg», en K. Nicolä̈DIS / R. Howse (dir.), The Feredal Vision: Legitimacy and levels of Governance in the United States and the European Union, Oxford University Press, 2001, pp. 54-70.

45 Cfr. M. Neves, Transconstitucionalismo, op. cit., p. 166.

46 G. Tusseau, «Un Chaos conceptuel qui fait sens: la rhétorique du constitutionnalisme global», op. cit., p. 210 .

47 Para una visión positiva del «diálogo», véase L. Burgorgue-Larsen, «Pour une approche dialogique du droit constitutionnel européen», en Mélanges V. Constantinesco. Europe(s), droit(s) européen(s), Bruylant, 2015, pp. 642-665. Una interpretación contraria se encuentra en : D. KENNEDY, «The Mystery of Global Governance», en J. L. Dunoff, J. P. Trachtman (dir.), Ruling the World. Constitutionalism, International Law, and Global Governance, Cambridge UP, 2009, pp. 37-68. Para otros trabajos desmitificando el «diálogo de los jueces», ver P.-Y. Monjal, P. Jan, CH. Geslot (dir.), La concurrence des juges en Europe : le dialogue des juges en question(s), éd. Clément Juglar, 2018. KavanaGH A., «The Lure and the Limits of Dialogue», University of Toronto LJ, Vol. 66, 2016.

48 Véanse en Francia las famosas sentencias Abdeli y Melki (Tribunal de Casación 16 de abril de 2010 y luego CJUE 22 de junio de 2010). A través de las mismas se articuló el nuevo mecanismo de cuestión prejudicial de constitucionalidad (llamado «QPC»), inaugurado por la reforma constitucional de 2008, a pasar por las Horcas caudinas del Derecho de la Unión. El Consejo Constitucional francés deberá revisar su interpretación inicial de la Ley Orgánica constitutivo de la QPC (seguido en su nueva lectura por el Consejo de Estado, sentencia Rujovic) para alinearse por anticipado sobre los requisitos del Tribunal de Justicia de la Unión Europea. Mientras que la «guerra» de los jueces fue evitada el «diálogo» perdió su aspecto equilibrado... Para un resumen más completo, S. PINON, «El sistema constitucional de Francia», ReDCE n. ${ }^{\circ} 14$, 2010, pp. 45-47. 
pacíficas, constructivas. Los políticos y los pueblos, que no tienen esta sabiduría, el mismo acceso a la razón, deben tomar nota. A fin de cuentas, hablar de «diálogo de los jueces» permite designar a los verdaderos «protagonistas iluminados» de la globalización, privados de miradas estratégicas. ¿Es posible creer esto seriamente? Detrás del diálogo se encuentra la sacralización de la función jurisdiccional que pretende oponerse a la bajeza de la actividad política. Como lo dice Mark Tushnet, son las ideologías las que se empacan con un manto de «teoría» para presentarlas como más académicas y menos comprometidas ${ }^{49}$.

Sin embargo, desarrollar tal visión maniquea vuelve a olvidar un poco rápidamente que la acción política contiene por esencia la acción colectiva. La llegada del constitucionalismo global contiene también otro peligro: el de una nueva concepción de la sociedad «hiper-individualista» y apolítica.

\section{UNA NUEVA COMBINACIÓN ENTRE LA DEPRECIACIÓN DEL POLÍTICO Y LA CENTRALIDAD DEL INDIVIDUO}

En su configuración actual e inconclusa, el constitucionalismo global podría resumirse como el paso de la soberanía del pueblo a la soberanía del individuo. El ser humano no sólo es el sujeto de derecho, sino también su causa y su finalidad exclusiva. Como lo expresa Anne Peters, «el proceso continuo de humanizar la soberanía es la piedra angular de la transformación actual del derecho internacional en un sistema centrado en los individuos» ${ }^{50}$. La «regla de oro del derecho global» emerge: ex persona oritur ius ${ }^{51}$. En palabras de Marcel Gauchet: «El mínimo poder social posible para la mayor libertad personal posible: tal es el nuevo ideal $»^{52}$. La jurisprudencia del Tribunal Europeo de Derechos Humanos fácilmente podría ilustrar una evolución que se traduce en «la elevación de los derechos humanos a la centralidad ideológica ${ }^{53}$. Pero se trata de derechos sobre todo civiles y políticos, porque la prioridad tras la Segunda Guerra Mundial fue pro-

49 M. Tushnet, Constitucionalismo y Judicial Review, Palestra Editores, 2017. En una línea próxima, P. A. IbÁÑez /G. M. Gallego García, Cultura constitucional de la jurisdicción, ed. Siglo del Hombre, 2011.

50 A. Peters, «Los méritos del constitucionalismo global», Revista Derecho del Estado, n. ${ }^{\circ} 40,2018$, p. 6.

51 R. Domingo, The New Global Law, op. cit., p. 125.

52 La condition politique, ed. Gallimard, coll. «tel», 2005, p. 541.

53 M. Gauchet, La démocratie contre elle-même, Gallimard, coll. tel, 2002. p. 340 . En su tesis doctoral (La prééminence du droit dans le droit de la Convention européenne des droits de l'bomme, Paris 1, 2011, publicada por Bruylant, 2012), X. Souvignet pone de relieve esta inclinación del TEDH a promover la superación de la democracia por el derecho. «Desconfianza hacia los derechos sociales, poco generosa con los derechos específicamente políticos, la Convención Europea de Derechos Humanos presenta así el retrato de un individuo único, racional, egoísta y poseedor, mirando el orden social y político de un ojo inquieto y grave, sospechando constantemente de querer jugar con sus libertades naturales y su propiedad». De todo esto se deriva un abandono progresivo del cuadro estatal así como una tentación de sustituir la «comunidad de derecho» por la «comunidad política». Véase también C. Colliot-Thelene, La democratie sans «demos», París, PUF, 2011. 
teger a los individuos contra la arbitrariedad del poder estatal, porque los regímenes comunistas que propugnaban la primacía de los derechos sociales colapsaron en beneficio de las corrientes ideológicas liberales (dominadas por las teorías de Hayek). Todo contribuye a privilegiar el individualismo en detrimento del comunitarismo y ecologismo, a privilegiar la libertad de los particulares, en detrimento de la fraternidad. Pero existe el riesgo de la pervivencia de la solidaridad nacional por la existencia de un exceso de individualismo, derechos egocentristas, reivindicaciones excesivas de la singularidad individual, un ideal construido alrededor del triunfo de los derechos subjetivos que puede debilitar el sentimiento de destino colectivo compartido y la aspiración al cumplimiento de los imperativos de interés general. La tentación «híper-individualista» de los derechos protegidos parece acentuada por el constitucionalismo global lo que genera un triple peligro.

El primero de esos peligros es el de conducir a una cierta forma de anexión de los derechos sociales por los derechos humanos

Si la globalización se manifiesta por la expansión del comercio, por la protección de la libertad contractual, de emprender, de invertir, por la omnipotencia de los mercados, a sensu contrario puede conducir a depreciar los derechos sociales, sobre todo cuando se debe combinarlos con las libertades individuales. ¿Qué representan, por ejemplo, los objetivos sociales del preámbulo del Acuerdo constitutivo de la OMC en relación con el principio de libre comercio? ¿Quién puede asegurar que la lógica de mercado y de eficacia se revele compatible con la idea de solidaridad consustancial a los derechos sociales? Bien es verdad que el fenómeno general de globalización de los cambios puede describirse como un proceso básicamente privatizador (incluso de bienes y servicios elementales), restrictivo desde el punto de vista electoral y creador de desigualdades. Ello sin hablar del reemplazo de organismos públicos de control de la economía por organismos de expertos, supuestamente independientes, como los Bancos centrales, las Agencias de evaluación o el Fondo Monetario Internacional. A la manera del economista Wolfgang Streeck, se podría decir que, en el mundo actual, los mercados financieros y las políticas fiscales se encuentran «inmunizados» contra los resultados electorados. «Un objetivo principal de los acreedores de los Estados es garantizar con toda seguridad que en tiempos de crisis sus reivindicaciones tendrán prioridad sobre las de los pueblos —es decir, garantizar el carácter prioritario del servicio de la deuda frente a las misiones estatales de servicio público» ${ }^{54}$. Por los franceses,

54 W. Streeck, Du temps acheté. La crise sans cesse ajournée du capitalisme démocratique, Gallimard, coll. Nrf Essais, 2014. p. 237 y 127. J. Habermas propone una respuesta crítica apasionante : «¿Democracia o capitalismo ?», Nueva Sociedad, julio-agosto de 2013, p. 32. 
¡que parece alejada el período de las grandes planificaciones tras la Segunda Guerra Mundial o la ola de nacionalizaciones dirigida por F. Mitterrand!

$\mathrm{Ni}$ siquiera en la esfera europea se puede esperar la inversión de la tendencia dominante: la de una constitución económica material que aplasta la perspectiva de una constitución social. Los célebres asuntos Viking y Laval (TJUE, 2007) lo recuerdan, así como el alcance jurídico limitado de la Carta Social Europea revisada en 1996. Incluso las jurisdicciones constitucionales nacionales sufren por el crecimiento sin control de los poderes económicos. Cada vez más abiertas a estas limitaciones exteriores neoliberales, dejan a la norma suprema imbuirse de lógicas económicas nuevas (equilibrio presupuestario, interdicción de las deudas públicas etcétera) capaces de amenazar la justiciabilidad de algunos derechos sociales. Dicho de otra manera, es la perspectiva de una constitución social aplastada por la constitución económica la que se perfila ${ }^{55}$. Por lo demás, si ciertos partidarios de la globalización se congratuan ante la perspectiva de una «desestatalización» del poder, no deben olvidar que el rostro del poder estatal no es sólo opresivo sino también un proveedor de servicios, de seguridad; debilitar el Estado es debilitar en el mismo tiempo el «Estado de bienestar» y alentar a su privatización. Pese al optimismo de los global professors, parece difícil encontrar en la esfera internacional - y hasta europea - a quien suceda eficazmente a la acción del Estado en materia de protección de los derechos sociales (la actualidad del coronavirus lo ilustra en el campo de la salud colectiva). Por ejemplo se puede comprobar que no son suficientes los progresos en la garantía del Pacto Internacional de Derechos Económicos, Sociales y Culturales para imponer una justiciabilidad efectiva de los derechos sociales entre los países signatarios ${ }^{56}$, y que la perspectiva de una verdadera política social unificada en la Unión Europa sigue siendo un «espejismo» integracionista. En el continente americano, ni el Protocolo adicional a la Convención Americana de San Salvador (aprobado en 1988 y que en vigor desde noviembre de 1999), ni la importante sentencia de la Corte Interamericana de Derechos Humanos del 1 de julio de 2009 (Acevedo Buendía y otros c. Peru ${ }^{57}$ ) permitirán invertir la tendencia. El número de recursos relativos a

55 El fenómeno se revela muy bien en el espacio europeo. Véanse las sentencias de 2007: TJUE, 11 de diciembre, Laval (C-438/05) y TJUE, 18 de diciembre Viking (C-341/05). Desde la aplicación de la Carta de los derechos fundamentales, TJUE 15 enero 2014 Association de médiation sociale c/ Union locale des syndicats CGT (C-176/12). Mientras que el derecho constitucional de los Estados miembros mantiene su neutralidad económica, la constitución supranacional de la Unión (tradicionalmente desarrollada por los jueces de Luxemburgo) acepta la primacía de la «racionalidad económica», de la libre competencia, incluso por los servicios públicos.

56 El Comité de Derechos Económicos, Sociales y Culturales (en activo desde 1989), hasta entonces competente para examinar los informes que los Estados partes presentan cada cinco años, está ahora en condiciones de examinar las reclamaciones individuales en caso de violación de los derechos reconocidos por el Pacto (Protocolo Facultativo aprobado por la Asamblea General de las Naciones Unidas el 10 de diciembre de 2008, ratificado por más de veinte Estados, que entró en vigor el 5 de mayo de 2013).

$57 \mathrm{La} \mathrm{CIDH}$ observa que el desarrollo progresivo de los derechos económicos, sociales y culturales ha sido objeto de pronunciamiento por parte del Comité de Derechos Económicos, Sociales y Culturales de las 
los derechos económicos y sociales ante la Corte de San José seguirá siendo limitado. Al mismo tiempo que caen las fronteras en numerosos campos, el nivel nacional sigue estando en primera línea en la realización de los derechos sociales fundamentales. Y más allá, en materia de protección contra las catástrofes naturales como la pandemia. Ante el desarrollo del Covid19 veamos marcadamente que resurge el Estado como garante principal de la salud de las personas y ente articulador de la gestión de la crisis (estado de urgencia, recurso a las fuerzas de seguridad, paquetes fiscales de compensación a empresas y trabajadores, restableciendo de las fronteras...). En realidad, el fenómeno de la globalización no parece abocar a la muerte de los Estados, sino a encontrarles una nueva posición en un contexto jurídico en plena transformación.

\section{El segundo peligro reside en la expulsión del poder político del constitucionalismo}

El constitucionalismo global mantiene una visión neoliberal de la sociedad, haciendo hincapié en la «forma» jurídica en detrimento de la «sustancia» política. Alienta, podríamos decir, un enfoque pasivo del hombre en la sociedad. Se le ha hecho la promesa de que será protegido en sus derechos olvidando recordarle que debe participar también en la determinación de un destino común. Por ejemplo, en la perspectiva «global» trazada por Anne Peters, las personas naturales (los individuos) serían «las personas jurídicas internacionales primarias y los miembros primarios de la comunidad constitucional global» ${ }^{58}$. El presupuesto básico de esta concepción de la subjetividad internacional es que, a partir de una interpretación teleológica del art. 6 de la DUDH y del art. 16.2 del PIDCP de 1966, los seres individuales no sólo tienen derecho a la personalidad jurídica en el derecho interno, sino que tendrían el derecho humano a tener personalidad jurídica internacional. Dicha subjetividad internacional implicaría por ejemplo el derecho a participar en los procesos de creación de normas internacionales y de

\footnotetext{
NU, en el sentido de que la plena efectividad de aquéllos «no podrá lograrse en un breve período de tiempo» y que, en esa medida, «requiere un dispositivo de flexibilidad necesaria que refleje las realidades del mundo (...) y las dificultades que implica para cada país el asegurar [dicha] efectividad». En el marco de dicha flexibilidad en cuanto a plazo y modalidades, el Estado tendrá esencialmente, aunque no exclusivamente, una obligación de hacer, o sea de adoptar providencias y brindar los medios y elementos necesarios para responder a las exigencias de efectividad de los derechos involucrados, siempre en la medida de los recursos económicos y financieros de que se disponga para el cumplimiento del respectivo compromiso internacional adquirido. Por más detalles, véase L. BuRGORGUE-LARSEN, «La transfiguración del trato de los derechos económicos y sociales en la jurisprudencia de la Corte Interamericana de los derechos humanos. Los anticipos del asunto Acevedo Buendía vs. Perú», Revista jurídica de la Derechos sociales, n. ${ }^{2}$ 2, 2012, p. 62. Otros fallos favorables a los derechos económicos y sociales los encontramos, por ejemplo de forma previa en Villaguay Morales e.a. cl Guatemala, 19 de noviembre de 1999 o Acevedo Jaramillo e.a. c/ Pérou, 7 de febrero de 2006.

58 A. Peters, «Membership in the Global Constitutional Community», J. Klabbers / A. Peters / G. Ulfstein, The Constitutionalization of International Law, op. cit., p. 157.
} 
activación de procedimientos judiciales o arbitrales; el derecho a la ejecución individual del derecho internacional tanto en el plano internacional como en el plano interno; el derecho a que tanto Estados como otros actores privados respeten sus derechos humanos; la posibilidad de que los individuos puedan exigir la responsabilidad internacional en algunos casos (las víctimas de violaciones de derecho internacional humanitario) etc. En suma, Anne Peters concluye que la transformación en marcha del individuo de sujeto de derecho internacional a ciudadano internacional forma parte de la evolución del ordenamiento jurídico internacional hacia una democracia constitucional universal. Los derechos y los individuos, cueste lo que cueste. Esta vía individualista implica la democratización de la gobernanza internacional por medio del ejercicio de la «ciudadanía transnacional» ${ }^{59}$.

A fin de cuentas, el discurso sobre el constitucionalismo global incurre con demasiada frecuencia en el desprecio del poder político estatal. Éste no es sólo un llamamiento a una humanización de la soberanía estatal por la multiplicación de los tratados de protección de derechos humanos, sino también un llamamiento a su desvalorización. Hasta Rafael Domingo considera la «soberanía» de los Estados como un concepto obsoleto, que obstaculiza la edificación de un derecho post-nacional ${ }^{60}$. Pero tal punto de vista equivale a pasar por alto el hecho de que, en ausencia de una democracia mundial, e incluso de una verdadera democracia europea, el Estado (sin olvidar las regiones autónomas o las entidades federales) sigue siendo el único vínculo de dependencia de la persona con la comunidad política. Se quiera o no, para la gran mayoría de los pueblos, el Estado todavía es la unidad básica de la democracia, el lugar de las elecciones importantes, el terreno de legitimación de los políticos más influyentes. La experiencia política determinante, la que hace el núcleo duro de la ciudadanía, continúa siendo nacional. Por lo tanto, despreciar en el futuro al Estado hoy equivale a desvalorizar el compromiso político, y por ende, a rechazar el equilibrio histórico —que fue desde el siglo dieciocho el pilar del constitucionalismo- entre la democracia y el liberalismo ${ }^{61}$. No debe olvidare que los conceptos tienen una profundidad histórica que sigue condicionándolos, ni olvidar la definición estricta del derecho constitucional: La Forma del Poder ${ }^{62}$.

En Francia, el profesor Slobodan Milacic viene avisando desde muchos años sobre el desequilibrio actual (y sus peligrosos) entre el liberalismo jurídico y la democracia política, entre el individualismo y el colectivo, entre la voluntad de

59 A. Peters, ibid., pp. 271-296.

60 R. Domingo, The New Global Law, op. cit., p. 99.

61 Para una crítica de esta tendencia en el contexto de los «chalecos amarillos» en Francia, véase nuestro estudio: S. PINON «La situación de Francia frente a los derechos fundamentales en el contexto del constitucionalismo multinivel», F. Balaguer Callejón, I. W. Sarlet (dir.), Derechos fundamentales, desarrollo y crisis del constitucionalismo multinivel. Libro homenaje a Jörg Luther, Thomson Reuters (en prensa).

62 F. Rubio Llorente, La Forma del Poder. CEPC, Madrid, 1993. 
la mayoría y la protección de las minorías ${ }^{63}$. De hecho, ¿cómo separar la norma y el voto? ¿La norma constitucional y el voto político? De cierta manera, el constitucionalismo global aceptaría que la norma no resultase de un voto (en asamblea legislativa o constituyente); el imperativo substantivo sin la dimensión formal. ¡Qué revolución epistemológica! ¡Qué riesgos! Algunos sectores de la población se asustan ante la desaparición de las comunidades nacionales políticas. Algunos partidos políticos parecen sufrir ansiedad colectiva. Se perfila la amenaza de un regreso violento del «inhibido político»; a través del populismo hoy día, en una parte cada vez más amplia de Europa (Italia, Hungría, Polonia, República Checa... $)^{64}$. La democracia «no liberal» (o «iliberal»), usando el triste concepto de Viktor Orbán... ¿Qué tipo de amenaza habrá mañana? Como lo escribe Cas Mudde, «el populismo es una respuesta democrática iliberal a un liberalismo que se ha vuelto antidemocrático» ${ }^{65}$. De hecho, la globalización del constitucionalismo, confiscada sobre todo por los jueces, refuerza la visión de una democracia «apolítica», sin debates, sin alternancia que permite a los adversarios del cosmopolitismo denunciar una integración de «las elites», opuesta a la voluntad de los pueblos. De esta manera los antieuropeos (las tendencias euroescépticas... las mismas que fomentaban el «Brexit») pueden usar de caricaturas oponiendo la «democracia jurídica» a la «democracia de las urnas».

El universalismo de los derechos contra las particularidades de las comunidades políticas; la legitimidad del conocimiento especializado, técnico, contra la legitimidad electoral. En numerosos discursos sobre la globalización, los individuos parecen perder el contacto con los Estados, como si fueran extraños a la geografía y a la historia. Un tipo de llamada del mar de las élites... que no puede compartirse con todos. Se dibuja una nueva forma de democracia que «expulsa» sus propias nociones claves: el «pueblo», la «ciudadanía», y a fin de cuentas la «política». Dicho de otra manera, el derecho constitucional, para muchos seguidores del «nuevo constitucionalismo», ha pasado a ser un derecho de la desconfianza, del «garantismo», y desde luego ha perdido su carácter de «legitimación»: legitimación al debate político, a la participación ciudadana, en definitiva, a la integración del pluralismo social. Triunfa el

63 S. Milacic, De l'âge idéologique à l'âge politique : écrits d'accompagnements, Bruylant, 2010. «Le néolibéralisme a imposé le règne de la norme libérale, par-dessus le vote démocratique (...). Aujourd'hui, la légitimité de la norme est dans sa nouvelle et fameuse «transparence» et, on n'a pas souvent idée d'aller vérifier la qualité substantielle et politique de la délibération et du compromis qu'elle exprime» (pp. XIV-XV). Del mismo autor : «Faut-il réinventer la démocratie ? Du «néodémocratisme» pour équilibrer le «néolibéralisme» «, Politeia, n. ${ }^{\circ}$ 6-2004, p. 447.

64 Cfr. P. Rosanvallon, Le siècle du populisme. Histoire, théorie, critique, Paris, Seuil, 2020. El autor divide la «anatomía» del populismo entre cuatros elementos principales: el «pueblo-uno» (que se une contra las élites y los extranjeros), la «democracia polarizada» (alrededor de las elecciones y de la primacía dada a la mayoría), el «hombre-pueblo» (el mito del «salvador» de la nación entera...) y el «nacional proteccionismo» en economía.

65 Según la fórmula de C. MudDe : «Populism in Europe: An Illiberal Democratic Response to Undemocratic Liberalism». Entrada en su artículo : «The Problem with Populism», The Guardian, 17 février 2015. También C. Mudde, C. Rovira Kaltwasser, Populism in Europe and the Americas: Threat or Corrective for Democracy? Cambridge, Cambridge University Press, 2012. 
dogma representativo con jueces erigidos como nuevos guías de la voluntad general, de la moralidad y de la felicidad colectiva. En suelo europeo, la sacralización del poder judicial — del TEDH, del TJUE - adopta el aspecto de una ideología. Se podría añadir que la hegemonía de los jueces acostumbra los conciudadanos a la dominación de los expertos, a una integración decidida en lugares lejos, cerrados. Una nueva forma de «epistocracía ${ }^{66}$. Antes que dar concreción al sueño de Platón de un gobierno de los filósofos, la epistocracía prefiere el poder de los altos funcionarios, de los especialistas en finanzas, en fiscalidad, competitividad, el poder de los peritos muy cualificados. Poniendo sus acciones bajo una casi objetividad científica, los sabios intentan imponer una visión única del mundo. Desaparece el debate ideológico y la pluralidad de las orientaciones políticas.

\section{EL DISCURSO DE LA CONVERGENCIA DE LOS DERECHOS Y EL IMPERIALISMO CULTURAL}

Los primeros discursos sobre el «constitucionalismo global» se encontraron dominados por la idea de convergencia o por la definición de valores «universales». Así, Anne-Marie Slaughter inauguró el concepto de «globalización judicial ${ }^{67}$ constatando la proliferación de mecanismos supranacionales de protección de los derechos (tratados, convenios, Tribunales internacionales, regionales etc.), y la importancia del «dialogo» informal entre cortes constitucionales de distintas latitudes o las citas de jurisprudencia de tribunales regionales de derechos humanos en los fallos de jueces nacionales. Estas nuevas interacciones multiniveles revelaban la permeabilidad creciente de los sistemas jurídicos al derecho internacional y al derecho comparado. Esta visión más abierta del orden jurídico nacional se extendió hasta la Corte constitucional de Suráfrica (la famosa sentencia State vs Markwanyane del 6 de junio de 1995), e incluso al seno de la Corte suprema de los Estados Unidos pese a su constatada reputación de patriotismo jurídico $^{68}$. A.M. Slaughter tenía la certidumbre de observar el nacimiento de un nuevo mundo: el de la constitución de una comunidad transnacional de jueces ${ }^{69}$, y de las primeras índoles de une democracia global ${ }^{70}$. Poco tiempo después, fue el éxito en la doctrina de nuevas expresiones como «diálogos globales y regionales»,

66 A. Viala (coord.), Demain l'épistocratie? (Actas del Congreso de Montpellier, 2017), Mare et Martin (pendiente de publicación).

67 A.-M. Slaughter, «Judicial Globalization», Virginia Journal of International Law, vol. 40, 2000, p. 1103.

68 Sobre este último punto, referirse a la sentencia Printz v. United States (1997) que dio lugar a una intensa controversia entre los jueces Breyer y Scalia sobre el uso de las sentencias extranjeras como modo de interpretar la Constitución. Para una referencia explícita a la jurisprudencia del TEDH, referirse a la sentencia Lawrence y Garner v. Texas (2003) que despenaliza las «leyes de sodomía» entre parejas homosexuales.

69 Cfr. «A Global Community of Courts», Harvard International Law Journal, n. ${ }^{\circ} 44,2003$, p. 191.

70 Cfr. «Building Global Democracy», Chicago Journal of International Law, 2000, p. 223. 
«sitios de producción y de recepción», «transjudicialismo», «convergencia ascendente, descendente y paralela» etc.

Se imponía la idea de una global «convergencia» de los órdenes jurídicos, sobre todo en el ámbito de los derechos humanos. Mark Tushnet ${ }^{71}$ habló del carácter «inevitable» de la globalización del derecho constitucional. Al respecto, la esfera europea podía aparecer como el primer laboratorio de este fenómeno de circulación y de estandarización de los derechos constitucionales. Numerosos son los indicadores que parecían demostrarlo: el activismo del Tribunal Europeo de Derechos Humanos, la redacción de la Carta fundamental de los derechos humanos de la Unión o la acción de la Comisión europea para la democracia por el derecho «Comisión de Venecia»), cada vez más cerca de un poder constituyente. Desde la reforma de su estatuto, en 2002, países que no son miembros del Consejo de Europa se pueden adherir como miembros a la Comisión. Así, algunos autores defienden la idea de un despliegue de «estándares europeos a vocación mundial $\gg^{72}$ en las áreas en las que está especializada (el funcionamiento de las instituciones democráticas y derechos fundamentales, justicia constitucional, elecciones, referendo y partidos políticos). Además de emitir sus recomendaciones destinados a los Estados, tuvo la iniciativa de crear la Conferencia Mundial de Justicia Constitucional que se reúne regularmente y congrega más de cien consejos de Tribunales procedentes de todo el mundo ${ }^{73}$.

Está visión común de los derechos humanos favorece enormes progresos. Pero existe otra cara de la moneda. En efecto, a través del aspecto ineluctable del discurso sobre la convergencia constitucional global aparecen muchas debilidades, tan metodológicas como culturales.

\section{Los límites del discurso sobre la convergencia desde un punto de vista metodológico}

Se observa que una gran parte de los exponentes del «constitucionalismo global» proceden de la misma manera que el dúo TEDH / Comisión de Venecia,

71 M. Tushnet, «The Inevitable Globalization of Constitutional Law», Virginia Journal of International Law, n. ${ }^{\circ}$ 49, 2009, p. 985.

72 V. MARTin, «La contribution de la Commission de Venise à la formation de standards constitutionnels mondiaux: vers un espace constitutionnel global?», M. DiSANT / G. LEWKOWICZ / P. TüRK (coord.), Les standards constitutionnels mondiaux, Bruxelles, Bruylant, coll. Penser le droit, 2017, p. 80. Entre otros estudios sobre el asunto, en esta misma revista: P. CRAIG, «Constitucionalismo transnacional: la contribución de la Comisión de Venecia», Teoría y Realidad Constitucional, n. ${ }^{\circ}$ 40, 2017, p. 79.

73 En febrero de 2019, el presidente del TC dominicano, M. Ray Guevara, insistió en que el intercambio jurisprudencial constituye una herramienta fundamental del derecho comparado para estudiar el derecho interno e ir armonizando legislaciones diversas, particularmente en el ámbito de la justicia constitucional, de los derechos humanos, de la democracia y del Estado de derecho. Recalcó también la importancia de la base de datos Códices que contiene más de diez mil decisiones judiciales, junto con constituciones, leyes sobre los tribunales y descripciones de las cortes que explican su funcionamiento. 
usando la «macro comparación» constitucional para deducir la presencia de una homogeneidad normativa (o el advenimiento futuro de tal homogeneidad). Se opta por cantidad frente a calidad. Hablar de «estándares mundiales» o de un «patrimonio constitucional común» a todos los países europeos implica conocerlos todos, lo que no es el caso. Los análisis se revelan muy a menudo superficiales, demasiadas formales, vacías de cultura constitucional. Lo que se revela obvio en los documentos producidos por la Comisión de Venecia. Todo conduce en fin a ver a sus miembros como «ingenieros» constitucionales listos para saltar de un avión hacia cualquiera de las cuatro esquinas del mundo para proveer su asesoría experta (sobre todo «occidental») acerca de la redacción de un texto constitucional ${ }^{74}$.

El enfoque cuantitativo se manifiesta por ejemplo a través del concepto de «consenso europeo», central en la jurisprudencia del TEDH. El Tribunal lo utiliza tanto para justificar un amplio «margen de apreciación» concedido a los Estados en ausencia de consenso (reproducción asistida, aborto, laicidad en las escuelas, por ejemplo), como para imponer «nuevos estándares» en los casos en los que existe una tendencia clara en la mayoría de los Estados miembros (igualdad de los hijos nacidos fuera del matrimonio u objeción de conciencia por citar algún ejemplo). Sin embargo, hay elementos que consideramos absurdos en este tipo de razonamiento. En primer lugar, la negación de lo que supone una constitución nacional: un «contrato social» entre generaciones, el reflejo de su propia historia, el código moral y cultural de un pueblo. Al fin y al cabo, un texto constitucional no es sino el reflejo de un «consenso interno» ${ }^{75}$. Desde luego, ¿cómo explicar a la mayoría de los ciudadanos que este «consenso interno» carece de valor...? ¡No vale si se establece un «consenso europeo»! Esta idea de absurdo que apuntábamos resulta también de la negación de los principios mismos que animan la historia del Consejo de Europa: el pluralismo, el respeto de todas las minorías culturales, sociales, étnicas frente a la tiranía mayoritaria. Finalmente, el respeto de las minorías... excepto las minorías constitucionales. En asuntos sociales de primer orden, el estándar dibujado por una mayoría de estados —inevitablemente flexible - no puede superar la voluntad del poder constituyente nacional.

En los análisis comparados no puede dejarse de lado «la constitución en sentido material» ${ }^{76}$. Como lo escribía Léontin-Jean Constantinesco, uno de los exponentes del derecho comparado, la ambición de este tipo de investigación no es de limitarse al derecho formal, sino de conocer el derecho real, es decir de

74 Según las formulas de R. HiRsChl, Comparative Matters. The Renaissance of Comparative Constitutional Law, Oxofrd, Oxford University Press, 2014, pp. 203-204. En castellano Asuntos comparativos. El renacimiento del derecho constitucional comparado, Colombia, Universidad Externado, 2019.

75 Para el caso español recomendamos la lectura de O. Alzaga Villaamil, Del consenso constituyente al conflicto permanente, Madrid, Trotta, 2011.

76 Cfr. C. Mortati, La Costituzione in senso materiale, ed. Giuffrè, Milano, 1940. (La Constitución en sentido material, trad. A. Belgareche Gros, Madrid, CEPC, 2001). 
inmiscuirse en «las fuentes sociales del derecho positivo» ${ }^{77}$. Al fin y al cabo, el discurso dominante del «constitucionalismo global» elige la concepción «universalista» del comparatismo, antes que la concepción «contextualista» (o «particularista»). El uso del derecho comparado se percibe como una útil herramienta para favorecer una convergencia a veces ilusoria de los derechos o de las instituciones. Es una tradición antigua. Cabe recordarse la organización del primer Congreso internacional de derecho comparado, en Paris, en 1900, y el contenido de la síntesis dada por Raymond Saleilles en la que el autor hablaba de una asignatura «independiente y autónoma» orientada hacia «la unidad fundamental de la vida jurídica universal» ${ }^{78}$.

Sus partidores son capaces de sugerir que la legitimidad constitucional de un país no depende solo de la calidad democrática y de la aproximación a los derechos en sus prácticas constitucionales, sino también de «cómo la Constitución nacional está integrada y cómo se relaciona con el mundo jurídico y político más allá de si misma» ${ }^{79}$. Pero enfatizar en exceso las similitudes transnacionales (mientras que los promotores del «contextualismo» tienden a sobreestimar las diferencias) puede conducir el universalismo hacia las fronteras inciertas del etnocentrismo o peor del neo colonialismo jurídico. Nos hallamos ante un menosprecio de las diferentes culturales.

Los límites del discurso sobre la convergencia global desde un punto de vista cultural

Una cuestión esencial se presenta: ¿Es posible que el «constitucionalismo global» sea solo un fenómeno de convergencia relativa entre Estados del «Norte»? ¿No es exagerado decir que los académicos que observan el «dialogo» generalizado de los tribunales nacionales y supranacionales o que concluyen a la estandarización mundial de los derechos humanos, nunca se apoyan en la situación del derecho en India, en Camerún, en Bolivia o en Madagascar? Desde luego, parece muy difícil aceptar el sello de la «universalidad» o del «global» cunando el cuerpo de conocimiento de las estudias comparadas no se refiere a la inmensa experiencia constitucional del «Global Sur» (aproximadamente doscientas constitucionales nacionales, cientos de miles de sentencias constitucionales...). «¿Es posible que el enfoque en el Norte constitucional revele no solo ciertas opciones metodológicas y epistemológicas, sino también una preferencia normativa por cierto grupo de valores que se percibe que mantiene

77 L.J. Constantinesco, Traité de droit comparé, tomo II, La méthode comparative, Paris, LGDJ, 1974, p. 216.

78 Véase M. AnCEL, Unité et méthodes du droit compare, Neuchâtel, Ides et Calendes, 1971, p. 17.

79 M. Kumm, "Constitutionalism and the Cosmopolitan State», Indiana Journal of Global Legal Studies, 20, 2013), p. 605. 
el Norte constitucional?» Para Ran Hirschl, la respuesta es «Si, ¡ciertamente! ${ }^{80}$.

En vez de un «constitucionalismo global» triunfaría un «universalismo occidental» basado en la superioridad de la ideología «neoliberal» (libertad individual y Estado de derecho $)^{81}$. Numerosos autores se interesan en esta deriva, con un grado de crítica diferente. Chery Saunders, por ejemplo, una prominente académica australiana del derecho constitucional comparado, subraya la ausencia de una plena consciencia de la experiencia global en su disciplina. «Buena parte del discurso del derecho constitucional comparado se enfoca en los sistemas constitucionales establecidos de Norteamérica y Europa además de algunos Estados externos con arreglos similares, basados sobre las mismas suposiciones ${ }^{82}$. Para el autor, la consecuencia inmediata de este etnocentrismo occidental es la evidente «marginalización» de las otras regiones del mundo, donde se ubica la mayor parte de los Estados. Ella explica que la marginalización puede tomar una variedad de forma: la ignorancia o el desprecio respecto a estas experiencias constitucionales particulares; la presunción según la cual los sistemas jurídicos del Sur reproducen el derecho del Norte (angloamericano o europeo) o proceden de ellos; el abandono del estudio de los regímenes específicos del otro mundo a los especialistas competentes en el campo de la antropología o de la sociología...

Un discurso similar se encuentra en los trabajos de Daniel Bonilla Maldonado. Según el autor, existe una «gramática» del constitucionalismo moderno moldeada adentro de un debate histórico entre tres polos: el liberalismo, el comunitarismo y el nacionalismo. Todos pertenecen a la historia global del «Norte». «Solo unas pocas instituciones, como el Tribunal Supremo de Estados Unidos, el Tribunal Europeo de Derechos Humanos y el Tribunal Constitucional alemán se consideran sujetos y agentes de referencia a la hora de interpretar las reglas y principios básicos del constitucionalismo moderno. Estas instituciones jurídicas son las que determinan el uso paradigmático de sus normas fundamentales, y son las responsables de definir y solucionar problemas políticos y jurídicos contemporáneos centrales, al darles un contenido específico a las reglas y principios del

80 R. Hirschl, Comparative Matters, op. cit., p. 206. Véase también: W. Menski, «Beyond Europe», en E. ÖrüCü / D. Nelken (coord.), Comparative Law : A Handbook, Hart Publishing, 2007, p. 191.

81 Véase J. Tully, Strange Multiplicity : Constitutionalism in an Age of Diversity, Cambridge, Cambridge University Press, 1995. El filósofo canadiense denuncia una visión de la democracia constitucional como un «imperio de uniformidad»; una forma moderna de imperialismo que rechaza el dialogo «intercultural». Para este autor el constitucionalismo moderno dominante se ve como una fuerza de la razón contra lo que presenta como irracional, diferente, como «el Otro», esto es, contra todo lo demás que no se suscriba a la visión liberal general. Su pensamiento pertenece al círculo del «multiculturalismo» (con CH. TAYLOR, W. KymLICKA), inspirado y provocado por el movimiento separatista quebequés. A la praxis del liberalismo prefieren una teoría de las minorías culturales. Todos subrayan los límites del proyecto liberal e universal de J. Rawls. Por un estudio reciente: A. SHINAR «The Ideologies of Global Constitutionalism», Global Constitutionalism, Vol. 8, 2019, p. 12.

82 C. SAunders, «Towards a Global Constitucional Gene Pool», National Taiwan University Law Review, 4, 2009), p. 3. 
constitucionalismo moderno ${ }^{83}$. El autor añade que la jurisprudencia de estas instituciones es leída y citada ampliamente por académicos e instituciones jurídicas de «muchas partes del globo», lo que deriva en una suerte de jerarquía «firmemente arraigada» en la política del conocimiento ${ }^{84}$. «En esta jerarquía, la investigación y las obras jurídicas creadas por el Sur Global ocupan una posición especialmente baja. No es habitual escuchar el nombre de un académico o de una institución jurídica del Sur Global en ese diálogo» ${ }^{85}$. Y, por último, se suele considerar que el subdesarrollo social, económico y político de estas regiones del mundo está directamente relacionado con su subdesarrollo jurídico. Este mismo autor intensifica la crítica al estudiar la actividad de tres tribunales: el Tribunal Supremo indio, el Tribunal Constitucional sudafricano y la Corte Constitucional colombiana ${ }^{86}$. En su opinión, la jurisprudencia transformadora de estos tribunales (en la esfera pública y civil de cada país), pese a un contexto muy violento, demuestra que merecen entrar en el gran relato del constitucionalismo moderno.

En la obra de Lucio Pegoraro, el tono acerbo toma la forma de una denuncia del «neoconstitucionalismo» ${ }^{87}$. Su punto de vista consiste en fijar el constitucionalismo del «Norte» en este concepto para descalificarlo mejor. ¿Qué es el «neo constitucionalismo»? Un concepto polisémico sin duda ninguna. Pero, recientemente, algunos académicos de América latina lo utilizan para denunciar una «vieja» (o clásica) maneja de enfocar la asignatura. En el «neoconstitucionalismo», el texto constitucional ha dejado de ser una simple forma de organización del poder o de distribución de competencias, para transformarse en un texto que debe acarrear la concreción de una serie de fines sustantivos. En concreto, la norma constitucional se vuelve invasora, por la positivización de un catálogo de derechos que se extienden al ámbito social, económico y por la omnipresencia de los Tribunales constitucionales... tan invasora que aplasta toda idea de participación directa del pueblo. Según Pegoraro, este tipo de constitucionalismo retoma

83 D. Bonilla Moldonado, «Prólogo. Hacía un constitucionalismo del Sur Global», en D. BoniLla Moldonado (coord.), Constitutionalism of the Global South: The Activist Tribunals of India, South Africa and Colombia, Cambridge, Cambridge University Press, 2013.

84 Véase del mismo autor, «La economía política del conocimiento jurídico», en D. Bonilla MoldoNADO, El constitucionalismo en el continente américano, Bogotá, Siglo del Hombre Editores, 2016. También: S.B. De Sousa, Una epistemología del Sur. La reinvención del conocimiento y la emancipación social, México, siglo XXI, 2009.

85 D. Bonilla Moldonado, «Prólogo. Hacia un constitucionalismo del Sur Global», op. cit., pp. 16-18.

$86 \mathrm{Ibid.,} \mathrm{p.} \mathrm{32.} \mathrm{Por} \mathrm{más} \mathrm{señas,} \mathrm{explora} \mathrm{la} \mathrm{jurisprudencia} \mathrm{de} \mathrm{los} \mathrm{tribunales} \mathrm{sobre} \mathrm{los} \mathrm{siguientes} \mathrm{asuntos:}$ derechos sociales y económicos, diversidad cultural y acceso a la justicia. A nuestro parecer, hubiera sido interesante añadir el activismo de la muy potente Corte Suprema de Brasil.

87 Véase L. Pegoraro, «Constitucionalización del derecho y cultura constitucional», Revista de Derecho Público, n. ${ }^{\circ} 104,2019$, p. 13. Otros autores (como R. Viciano, R. Martínez Dalmau o C. Bernal Pulido) utilizan el concepto de «neoconstitucionalismo» para poner de relieve el aspecto realmente «nuevo» del constitucionalismo nacido al fin del siglo veinte en América latina (en Colombia, Venezuela, Bolivia y Ecuador). El enfoque permite a la vez un fuerte rechazo hacia el colonialismo institucional norteamericano y una reacción frente a la uniformización cultural en tiempos de globalización. 
«la idea básica de la superioridad de los derechos humanos, rechazando sin embargo de hecho la superioridad de la constitución como ley fundamental decidida soberanamente por cada sociedad y el propio concepto de soberanía, además de la división de poderes, a favor de los Tribunales constitucionales, de los Tribunales internacionales, de la soft law producida fuera o al margen del circuito de legitimidad democrática» ${ }^{88}$. Por consiguiente, es fácil deducir que el «constitucionalismo global» se le muestra como una ficción de tipo «occidental». «El jurista occidental no parece entender, en toda su gravedad, los cambios que cada vez más afectan a los fenómenos jurídicos. Prefiere, de hecho, continuar usando una dimensión etnocéntrica de los ordenamientos como una práctica puramente euroatlántica». Bajo la influencia del «positivismo legislativo», no plantea la interrogación de si y cuando el fermento cultural pertenece a la esfera de lo jurídico, al menos en aquellos ordenamientos que no aceptan el Derecho occidental ${ }^{89}$. En otras palabras, al profesor Pegoraro le preocupa delimitar y especificar en qué consiste el «occidente jurídico».

Hay tres efectos más llamativos de esta supremacía del «occidente jurídico»: primero, «una invasiva judicialización de la política y la concesión a los jueces de incontrolables funciones de decisión política». Para el autor, esta corriente, alimentada por estudiosos de diferentes países ${ }^{90}$, puede ser utilizada para legitimar el «no Derecho» de la globalización ${ }^{91}$. Segundo, cabe subrayar que el «neoconstitucionalismo» se pretende aplicar — y de hecho se aplica— no solo donde hay coherencia entre textos constitucionales y cultura jurídica liberal-democrática, sino también en todos otros países de cualquier continente (Japón, Irak, Afganistán, Timor oriental etc.). Tercero, es el horizonte de una muerte de la rama «contextualista» de la ciencia comparada que se anuncia, «en virtud de su irrelevancia de cara a fenómenos como la convergencia transnacional y la llamada armonización de un Derecho común $»^{92}$. A pesar del riesgo de «choque de civilizaciones», Pegoraro finaliza su estudio con un punto de optimismo, poniendo de manifiesto la «parcial resistencia» a los fenómenos de globalización de algunos países de América latina, de África Austral o de Asia. De facto, observa que consiguen experimentar «soluciones originales», que tutelan las antiguas raíces y que retoman valores perdidos de equilibrio entre factores distintos (el individuo, la comunidad, la naturaleza; los derechos y los deberes; la libertad, la igualdad, la fraternidad), pro-

88 Ibid., p. 30.

89 Ibid., p. 20

90 En Francia, fue el profesor L. FAvoreu el que inició la visión del derecho constitucional como una invasiva judicialización de la política (Véase, La politique saisie par le droit, Paris, Economica, 1988). Pero en la actualidad son numerosos los autores contrarios a esta doctrina (O. BEAUD por ejemplo). Se la acusa de negar la dimensión filosófica y política del derecho constitucional.

91 L. Pegoraro, «Constitucionalización del derecho y cultura constitucional», op. cit., p. 31. También, C. Escobar-García, « ¿Constitucionalismo global? Vicisitudes y contingencias del proceso a partir de algunas experiencias en América latina», Díkaion. Revista de Fundamentación Jurídica, Vol. 21, 2012, p. 79.

92 Ibid., p. 50. 
pios de muchas culturas autóctonas, pero también del cristianismo y del socialismo. En suma, un conjunto de nuevos razonamientos jurídicos que puede, a corto plazo, «fertilizar el constitucionalismo mundial ${ }^{93}$.

\section{CONCLUSIONES}

El problema de la «falsa universalidad» se revela en definitiva tanto a nivel global como europeo. Se observa un mismo proceso de estandarización de los derechos fundamentales que conduce a la misma negación de la «diversidad cultural». Es una de las debilidades de la construcción europea: hacer una Europa de los valores universales, de los valores comunes (con el riesgo de inventarlos), desvalorizando al mismo tiempo la importancia de las singularidades nacionales. Es el desequilibrio entre la «identidad europea» y las «identidades constitucionales nacionales» el que puede despertar el populismo. La interacción inevitable en un espacio integrado no debe transformarse en una subordinación de las segundas ${ }^{94}$. Expresado de otra forma, la mecánica de la integración europea olvidó desde el inicio la escuela «culturalista» del derecho — «law is culture»— según la cual el derecho (sobre todo público) no se entiende sin considerar su propio contexto, su historia ${ }^{95}$. Hoy día, el populismo nacionalista se desarrolla sobre todo en el Este de la Unión europea (en Hungría, Polonia, República Checa, Eslovaquia, Croacia...). No es, en absoluto, una casualidad. Consideramos que este fenómeno encuentra explicación por el peso de la Iglesia cristiana en estas regiones de Europa, con sus valores cada vez más cuestionados por la interpretación de los derechos fundamentales (homosexualidad, aborto, libertad sexual etc.). El iusnaturalismo de la Iglesia no coincide con la interpretación «evolutiva» de los derechos fundamentales garantizada desde Estrasburgo ${ }^{96}$. A mayor abundamiento, estos países del Este

93 Ibid., pp. 55-56. La perspectiva de una fertilización cultural cruzada se acerca de la visión de un «constitucionalismo orgánico global» defendida por CH. SchwöBEL-PATEL. No quiere tampoco ella una «falsa universalidad» que no logre dar cuenta de las concepciones y estructurales locales del derecho. Utiliza los mismos términos de «imperialismo» y de «colonialismo» para denunciar la universalización de los solos valores occidentales. Al constitucionalismo fijo actual, de talla única, prefiere el concepto de «universal negativo». CH. SCHwöBel-PATEL, Global Constitutionalism in International Legal Perspective, Martinus Nijhoff, Leiden, 2011, p. 148 o «Situation the Debate on Global Constitutionalism», International Journal of Constitutional Law, Vol. 8(3), 2010, p. 611.

94 En un libro reciente, el intelectual R. Debray (L'Europe fantôme, Gallimard, 2019) subraya el fenómeno. Después de la famosa sentencia Lautsi c. Italy de 2011, el TJUE en la sentencia de 5 de diciembre de 2017 M.A.S. et M.B., ha dada prioridad al respeto de la «identidad nacional» sobre los imperativos de unidad y de primacía del derecho de la Unión. Quizás sea el inicio de una inflexión a favor de la diversidad constitucional tras cincuenta años de uniformización y de monólogo.

95 En Francia, P. LEgrand (Le droit comparé, PUF, coll. Que sais-je? 1999) es un partidario de la «escuela» culturalista. Así se opone al método «funcionalista» desarrollado por K. ZweigerT y H. KöTZ. J. BELL o R. SACCO fueron otros críticos del método «funcionalista».

96 «La era de la democracia liberal ha terminado porque no podía ya ofrecer la libertad, garantizar la seguridad y mantener vivo el cristianismo», declaró Viktor Orbán en el Parlamento (10 de mayo de 2018), en 
vivían bajo el totalitarismo soviético como sociedades cerradas, sin tradición de emigración extramuros de las fronteras del continente, sin conocer la religión del islam o el multiculturalismo de las sociedades occidentales. Se plantea aquí un doble problema: el de la resistencia de la tradición ante la globalización y el de los ciudadanos de la nación-Estado ante los ciudadanos del mundo. Esta fue una de las explicaciones del voto a favor del Brexit en su momento y puede también aclarar la presencia de un «constitucionalismo contra-hegemónico» en el Sur Global (Bután, Ecuador, India, Namibia o Túnez, por citar algunos), con otra lectura de la fraternidad, de la religión o con la preferencia dada al «interculturalismo».

Son evidentes los cambios que se produjeron en el derecho constitucional desde la Segunda Guerra Mundial, especialmente en suelo europeo. En el transcurso del proceso de integración (desde la Europa de los «seis» hasta la Europa de los «veintiocho», ahora «veintisiete»), nació un genuino «Derecho constitucional europeo» ${ }^{97}$. Pese a las resistencias, aun académicas, las metamorfosis fueron relevantes. La «europeización» de los órdenes jurídicos nacionales se vuelve una realidad y no sólo en el campo del derecho público. Pero, ¿qué decir de la «globalización» del derecho constitucional? ¿Nos encontramos quizá ante la siguiente etapa en este proceso evolutivo? ¿Una etapa inevitable? ¿De qué forma ${ }^{98}$ ? La legitimidad del orden global plantea otra cuestión: la relativa a la manera de conseguir la legitimidad de las reglas e instituciones internacionales. ¿Una legitimidad plural (de la imparcialidad, de la eficacia, de la protección de la salud, del medio ambiente)? Pero además de este tipo de legitimidad «funcional», todo pacto constitucional exige la presencia de una legitimidad "política».

Existen indicadores fuertes para afirmar que el Derecho constitucional está en el umbral de una nueva etapa. Con varios miles de millones de personas confinadas en el mundo, la crisis sanitaria prueba, dice Luigi Ferrajoli, que sólo las «soluciones globales» garantizan nuestra supervivencia ${ }^{99}$. Dejando la actualidad inmediata, se observa la irrupción de múltiples sistemas normativos, que mantienen un juego de autonomía, complementariedad y concurrencia con el Estado. Las pérdidas de centralidad y unidad en los procesos de regulación socio-jurídica, como consecuencia de la interconexión global, hace cada vez más complejos y transversales los conflictos de fuentes del derecho. Esta nueva configuración «policéntrica» y abierta ha cambiado tan las funciones del Estado como sus estructuras. Y como existe una histórica interdependencia entre el Estado y la

su primer discurso tras ser reelegido jefe del Gobierno por tercera vez consecutiva gracias a la mayoría absoluta de su partido, el Fidesz.

97 A este respecto, debemos saludar el nacimiento tiempo atrás (en una época de repliegue de la doctrina constitucionalista sobre la herencia estatal) de la Revista de derecho constitucional europeo, dirigida desde la Universidad de Granada (ReDCE: https://www.ugr.es/ redce/).

98 M. Rosenfeld propone otra pregunta: «Is Global Constitutionalism Meaningful or Desirable?», European Journal of International Law, n. ${ }^{\circ} 25,2014$, p. 177.

99 El País («Una Constitución para el mundo») de 5 de abril de 2020. 
Constitución, es el Derecho constitucional mismo el que entra en una fase de profunda mutación. No ha permanecido ajeno al contradictorio y vertiginoso impacto de estos procesos de mundialización y de crisis de la soberanía ${ }^{100}$. Pero, ¿en qué medida se produce esta una mutación? ¿Con qué horizonte?

Se despliega, sobre todo el en «Norte Global», con estándares de derechos humanos y mecanismos multiniveles para garantizarlos. Algunos autores prefieren hablar del crecimiento de una «cultura constitucional» global antes que de una «constitución» ${ }^{101}$, mientras que otros ven el constitucionalismo global como «una promesa para el futuro» ${ }^{102}$ o un simple «proceso» de constitucionalización. Podríamos también permanecer en el léxico del derecho internacional para describirlo y observar su tendencia a la humanización. Lo hemos apuntado en la introducción de este estudio, existen tres diferentes discursos sobre el "constitucionalismo global»: uno que enaltece el proceso actual de globalización de los derechos acercándolo al nacimiento de una constitución en sentido material; otro que desea amplificar la realidad concreta; y un tercero que intenta dibujar un nuevo mundo global. Por ende, el «constitucionalismo global» pertenece ante todo al lenguaje de la doctrina, pero menos al derecho positivo.

Es bien sabido que «el problema no estriba jamás en cómo meterse en la cabeza ideas nuevas e innovadoras, sino en cómo sacarse de ella las viejas». Pero el constitucionalismo global no se opone sólo a las ideas (el encierro del derecho constitucional en las fronteras de la «nación-Estado» en primer lugar) sino también a las realidades. Son las realidades que interponen obstáculos ante el advenimiento de un verdadero «constitucionalismo global»: la oposición entre la cultura del Norte y las culturales del Sur, la oposición entre la herencia del colonialismo y la voluntad de tutelar las raíces (el reconocimiento constitucional de los pueblos indígenas por ejemplo), el mundo islámico, el confucionismo, los nuevos imperios autoritarios (Rusia, China) que se refuerzan a medida que se debilita el mundo occidental ${ }^{103}$. Las divisiones geopolíticas endémicas excluyen cualquier cuestión vinculada a una suerte de gobierno mundial. Dicho de otro modo, hay una oposición entre la globalización material (de la energía, de los médicos, de los diferentes redes de producción...) y el repliegue mental o intelectual. El Covid19 ha desenmascarado la ausencia de una consciencia planetaria. Paul Valéry lo subrayaba ya a principios del siglo $\mathrm{xx}$, el drama es que la inteligencia colectiva no evoluciona al mismo ritmo que la ciencia.

100 A. De Cabo De La Vega, G. Pisarello (coord.), Constitucionalismo, mundializacíon y crisis del concepto de soberanía. Algunos efectos en América latina y en Europa, Monografías, Universidad de Alicante, 2000.

101 A. Atilgan, Global constitutionalism. A Social-Legal Perspective, Berlin, Springer, 2017.

102 CH. SCHwöBel-PATel, Global Constitutionalism in International Legal Perspective, op. cit., p. 551. Sobre el autor, referirse también a la estudia de A. J. RoDRIGO: «El pluralismo del constitucionalismo internacional», Anuario español de derecho internacional, vol. 29, 2013, p. 94.

103 No nos extrañaría que la crisis del «coronavirus» agrave la tendencia. 
Probablemente sería apasionante desarrollar una arquitectura normativa de tipo constitucional que sirviera de «brújula» de todos los gobiernos para el buen gobierno. Pero lo cierto es que no todos los gobiernos y sobre todo no todos los pueblos lo quieren. ¡Cabe recordar las resistencias inexpugnables en Europa frente al horizonte federal... y frente a un «Tratado constitucional» ${ }^{104}$

En síntesis, diríamos que hay dos maneras de ver el «constitucionalismo global»: una que lo condena, otra que lo asiste. La primera es unívoca, monolítica, normativista, y se apoya sobre una lógica de sustitución: la ciudadanía mundial en el sitio de la ciudadanía nacional, la democracia mundial y europea en el sitio de la democracia estatal, etc. La segunda manera de ver el constitucionalismo global es más pragmática, más abierta, dialéctica, basada en una lógica de subsidiaridad y de coorganización; el marco estatal se mantiene dentro de una articulación con otras autoridades públicas supranacionales. Este último tipo de constitucionalismo se acerca del esquema europeo, muy a menudo presentado como un multilevel constitutionalism, un constitucionalismo "compuesto» o un «pluralismo constitucional» articulado. Consiste en pensar juntos los espacios jurídicos (nacionales, infra, supranacionales...) y sus modalidades de articulación. Pero ya sabemos que el modelo europeo no reúne las características adecuadas para trasladarse con éxito al plano global: contribuye demasiado a la homogeneidad de los órdenes jurídicos; no resulta suficientemente protector en el ámbito social; presenta un aspecto demasiado «tecnocrático»; no es suficiente irrigado por la legitimidad parlamentaria... Por lo tanto, al elegir la segunda manera de ver el constitucionalismo global, a pesar de su índole pragmática y modesta, seguimos siendo en el campo de los sueños o de la utopía. De hecho, ¿cómo articular el pluralismo multidimensional (a la vez normativo, político, histórico, religioso, antropológico...) al nivel mundial? ¡Imaginar la perspectiva de una «verticalización» del constitucionalismo sería una broma!

En síntesis, el desafío del «pluralismo» global se asemeja a los desafíos del «multipartidismo político» conocidos en los Estados. En los regímenes parlamentarios, se comprueba que el multipartidismo de la representación abre dos vías: o el camino del consenso, del punto de encuentro entre la diversidad de las reivindicaciones, de las concesiones reciprocas entre los partidos políticos, de la primacía del interés general sobre los intereses particulares, o el camino muy peligroso de la parálisis. En el primer caso, hablaríamos de unos «Pactos de la Moncloa» al nivel mundial, mientras que el segundo recuerda el régimen de Weimar, la Cuarta República en Francia, el régimen belga desde hace diez años o el régimen español desde hace un lustro. ¿Cómo evitar la misma parálisis a nivel global? A nuestro juicio se necesitaría la confluencia de dos elementos: la desaparición de todas las dictaduras o de todos los totalitarismos (según la antigua idea de un paralelo entre la subida de la democracia y el fortalecimiento de

104 Sobre esta cuestión puede verse el n. ${ }^{\circ} 15$ de la revista Teoría y Realidad Constitucional. 
la $\mathrm{paz}^{105}$ ) y el de un «relativismo filosófico». Hans Kelsen ofrece la presentación siguiente de este segundo elemento de la siguiente forma: «La tolerancia, los derechos minoritarios, la libertad de expresión y la libertad de pensamiento no tienen calidad en un sistema político basado en la creencia en valores absolutos (...). Esta consecuencia de los principios de libertad e igualdad es justificable sólo si no existe una respuesta absoluta a la pregunta de qué es lo mejor, si no existe algo así como un bien absoluto» ${ }^{106}$. Y por último, se necesitaría un cambio en el propio ciudadano, llave de bóveda de la democracia. Es el desafío mayor. Como recuerda Giovanni Sartori ${ }^{107}$, Ortega y Gasset describió en un libro «muy inteligente» (La rebelión de las masas, 1930) la llegada de un nuevo tipo de ciudadano: el «hombre-masa». Es un niño malcriado e ingrato que recibe en herencia unos beneficios que no merece y que, por consiguiente, no aprecia. Ortega y Gasset hablaba de un hombre debilitado, «ablandado», «invertebrado». Tenemos dudas de que el «hombre-digital» de nuestra modernidad sea mejor. ¿Será acaso capaz de afrontar los retos de la democracia enfrentada al populismo? ¿Y los retos del pluralismo global?

En la rica e imprevisible historia de la «democracia», tuvo lugar el advenimiento del «pueblo-elector» (sufragio universal, partidos políticos, voto de las mujeres), después el advenimiento del «pueblo-social» (derecho de huelga, sindicatos, Estado social, exigencia del «dialogo social» durante la elaboración de la ley...), hoy día se observa la llegada del «pueblo-digitalizado» (internet y nuevas redes de comunicaciones), y pronto del «pueblo-aumentado» por el transhumanismo. El «pueblo digitalizado» es un pueblo débil; el pueblo de elecciones como las de Trump, Bolsonaro, o el movimiento 5 estrellas, por citar algunos claros ejemplos. El «hombre-digital» tiene la certidumbre de su emancipación política (con la nueva estrategia inquisitoria de la transparencia, con la custodia permanente de todos los actores políticos, la difusión de un nuevo tipo de antiparlamentarismo...) y de su realización personal (empowerment en la expresión anglosajona), sin saber que al mismo tiempo entra en un mundo de la esclavitud difusa. Desaparece en efecto la pluralidad de los medios de informaciones, devorada por los gigantes de la comunicación, Facebook en primer lugar. Pero lo cierto es que al «hombre-digital» esto le importa limitadamente. Deja miles de huellas numéricas que los algoritmos

105 Desde E. Kant hasta G. Scelle o B. Mirkine-Guetzevith por ejemplo. Véase B. MirkiNe-Guetzetich, Droit constitutionnel international, Paris, Sirey, 1933 ; «Les tendances internationales des nouvelles constitutions», Revue générale de Droit international public, n. ${ }^{\circ} 3-4,1948$, p. 375.

106 H. Kelsen, What is Justice? Justice, Law and Politics in the Mirror of Science. Collected Essays by Hans Kelsen, University of California Press, Berkeley-Los Angeles-London, 1971, p. 206. El profesor austriaco adopta otra fórmula en su libro Esencia y valor de la democracia: «Existe por un lado una cierta conexión entre la concepción metafísica-absolutista del mundo et una actitud en favor de la autocracia y, por otro lado, entre una actitud en favor de la democracia e una concepción critica-relativista del mundo». H. KelSEN, La démocratie — sa nature, sa valeur, 1932, rééd Dalloz, 2004, p. 111 (capítulo X). La primera edición de 1920 (Wesen und Wert der Demokratie) fue publicada en castellano; en castellano se ha consultado la versión editada por Comares, Granada, 2002.

107 G. SARTORI, La democracia en treinta lecciones, Edición a cargo de L. Foschini, Taurus, 2009, p. 144. 
utilizan frenéticamente para vender mejor, trazar sus comportamientos, orientarle mejor. Las $G A F A M$ le halagan para domesticarle mejor. Se acerca a un hacking sobre los seres humanos. Pero, a nuestro juicio, al «hombre-digital» esto no le interesa. La «revolución» de la sociedad digital tiene un alcance multidimensional: cultural, educativo, antropológico, económico, militar etc. Para evitar el reino, si se nos permite la expresión, del «tonto-digital» ${ }^{108}$, se debe implementar un programa educativo a gran escala por las nuevas generaciones: fomentar el pensamiento crítico ante las redes sociales y la inteligencia artificial. Nos encontramos sin duda ante uno de los grandes retos de la humanidad.

La historia muestra que el éxito del constitucionalismo democrático al nivel estatal depende de la educación del pueblo. En la actualidad, los nuevos «pueblos digitalizados» no tienen la capacidad de afrontar el desafío de un constitucionalismo democrático al nivel mundial.

\section{$* * *$}

\section{TITLE: Uncertainties of Global Constitutionalism}

ABSTRACT: In the juridical discourses the references to the global constitutionalism are multiplying themselves, in particular since the arrival of the Covid 19. This concept, in the middle of construction, appears as a solution as well as a problem, confronted to the development of the globalization and the interaction between the juridical actors. This study is prioritizing the second aspect. The playwright Jean Giraudoux used this formula: «the law is the most powerful of schools for the imagination. No poet ever interpreted nature as freely as a lawyer interprets the truth». Beyond the utopias, I'd rather underline three points: the perspective of a new type of oligarchy behind the global constitutionalism; the threats of a combination of the devaluation of the political power and the centrality of the individual; and eventually the discourse to the convergence of the buman rights, which bides the presence of a cultural imperialism. To conclude, inside this reflexion about the global constitutionalism, how to consider the European constitutional law: as a role model to follow, or as a model to reject?

RESUMEN: En los discursos jurídicos se multiplican las referencias al «constitucionalismo global», sobre todo desde que brotó la pandemia del covid19. El concepto en fase de construcción aparece a la vez como una solución y como un problema ante el desarrollo de la globalización y de la interacción entre los actores jurídicos. Nuestro estudio privilegia el segundo aspecto. El dramaturgo Jean Giraudoux planteó que «El derecho es la más poderosa escuela de la imaginación. Nunca poeta ninguno ba interpretado la naturaleza tan libremente como un jurista la realidad». Más allá de los sueños, preferimos poner de relieve tres puntos: la perspectiva de un nuevo tipo de oligarquía tras el constitucionalismo global, las amenazas de una combinación entre la depreciación del «político» y la centralidad del individuo, el discurso de la convergencia de los derechos bumanos que desenmascara la presencia de un imperialismo cultural. Enfocado al constitucionalismo global, ¿qué hacer del derecho constitucional europeo: un modelo sugestivo o perturbador?

KEY WORDS: Legal realism, Legal pluralism, Judicial dialogue, Supranational jurisdictions, Constitutional standards, Epistocracy, Social rights, Comparative law, Legitimacy, Transnational citizenship, Illiberal democracy, Populism, Global north and Global south, Western universalism, New constitutionalism, Multilevel constitutionalism.

108 M. DeSMURGet, La fabrique du crétin digital. Les dangers des écrans pour nos enfants, Seuil, 2019. 
Palabras Clave: Teoría realista de la interpretación, Pluralismo jurídico, Dialogo entre jueces, Jurisdicciones supranacionales, Estándares constitucionales, Epistocracía, Derechos sociales, Derecho comparado, Legitimidad, Ciudadanía transnacional, Democracia no liberal, Populismo, Global norte y Global sur, Universalismo occidental, Nuevo constitucionalismo, Constitucionalismo multinivel.

FECHA DE RECEPCIÓN: 14.04.2020 FECHA DE ACEPTACIÓN: 09.09.2020 